\title{
APROXIMACIÓN CRIMINOLÓGICA A LA PRISIÓN PERMANENTE REVISABLE
}

\author{
Alberto Pintado Alcázar \\ Universidad de Murcia \\ E-mail: alberto.pintado@,um.es
}

\begin{abstract}
RESUMEN: La presente investigación comprende un estudio teórico y empírico relacionado con la prisión permanente revisable, la cual, a pesar de llevar en vigor pocos años en nuestro Código Penal, se configura como una condena de gran repercusión dogmática y social. En consecuencia, los dos pilares sobre los que se sustenta el debate generado se establecen en la gravedad de los hechos delictivos cometidos por las personas condenadas por la misma y en la duración de la mencionada condena.
\end{abstract}

Palabras clave: prisión permanente revisable, condena, Código Penal, Criminología, reforma.

\begin{abstract}
The present research includes a theoretical empirical study related to the revisable permanent prison, which, despite having been in force for a few years in our Penal Code, is configured as a sentence of great dogmatic and social repercussion. Consequently, the two pillars on which the debate generated is based are established in the seriousness of the criminal acts committed by the people convicted and in the duration of the aforementioned sentence.
\end{abstract}

Keywords: revisable permanent prison, conviction, Penal Code, Criminology, reform.

SUMARIO: I. INTRoducción. II. BREVE REFERENCIA históriCa. 2.1. Código penal de 1822. 2.2. Código penal de 1848. 2.3. Código penal de 1870. 2.4. Código penal de 1928. 2.5. Código penal de 1932. 2.6. Código penal de 1944. 2.7. Código penal de 1995. III. Configuración de la prisión permanente ReVisable. 3.1. Manifestaciones a favor o en contra de la prisión permanente revisable. 3.2. Incidencia de la prisión permanente revisable dentro de la normativa penitenciaria. 3.3. Aplicabilidad de la prisión permanente revisable en el código penal. IV. ANÁLISIS CRIMINOLÓGICO DE LA APLICACIÓN DE LA PRISIÓN PERMANENTE REVISABLE EN ESPAÑa. 4.1. Criterios criminológicos. V. CRITERIos PENALES. V. Conclusiones. VI. Bibliografía

\section{INTRODUCCIÓN}

La aparición de nuevas conductas merecedoras de un castigo penal, la evolución constante de la ciudadanía, así como la influencia que ejercen determinados agentes sociales, 
pueden llegar a provocar la necesidad de establecer diversas reformas en nuestro Código Penal. En este sentido, en referencia al desarrollo que sufre diga Ley Orgánica, Morillas Cueva dispone que "a lo mejor un día el Derecho Penal se muestra incensario para la resolución de los conflictos sociales más graves, precisamente porque estos no existan, suprimidos por grandes dosis de solidaridad, de igualdad y de libertad. Mientras tanto, y me temo que por mucho tiempo, es imprescindible conseguir un Derecho punitivo verdadero protector de todos los Derechos Humanos, y una educación y compromiso entre los ciudadanos que hagan inviable la destrucción gratuita, aberrante e incomprensible de bienes jurídicos del más alto nivel, entre ellos la vida".

La entrada de la prisión permanente revisable dentro del conglomerado de penas ha generado mucha polémica, tanto en la sociedad en su conjunto, como dentro de la doctrina penalista, donde existen dos grandes grupos confrontados; aquellos que la ven como una sanción desproporcionada e inconstitucional frente a aquellos que consideran necesaria la implantación de esta medida para intentar evitar, por ejemplo, la reincidencia de determinados delincuentes.

A tenor de lo anteriormente citado, es conveniente referenciar el artículo 25.2 de la Constitución Española, el cual se considera como uno de los preceptos principales dentro de la configuración penitenciaria nacional. Así, dicho artículo establece que "las penas privativas de libertad y las medidas de seguridad estarán orientadas hacia la reeducación y reinserción social y no podrán consistir en trabajos forzados. El condenado a pena de prisión que estuviere cumpliendo la misma gozará de los derechos fundamentales de este Capítulo, a excepción de los que se vean expresamente limitados por el contenido del fallo condenatorio, el sentido de la pena y la ley penitenciaria". En consecuencia, se genera un dilatado interrogante a la hora de poder determinar si en dicha sanción se podrían aplicar los criterios necesarios para que los infractores puedan llegar a reinsertarse en la sociedad.

Llegados a este punto, considero determinante hacer referencia a la definición de pena, recalcando lo establecido por Mapelli Caffarena, quien afirma que es "una institución de derecho público que limita un derecho a una persona física (o jurídica) e imputable como consecuencia de una infracción criminal impuesto en una sentencia firme por un órgano judicial"'2.

Por otro lado, cabe destacar que existen multitud de países donde se impone una sanción que presenta características similares a las contempladas dentro de la prisión permanente revisable, estableciéndose con ello la existencia de condenas a perpetuidad. Así, a modo de ejemplo, el Código criminal alemán (Strafgesetzbuch) establece que "la pena privativa de libertad es temporal, salvo que la ley imponga pena perpetua", afirmando con ello la posibilidad de que a los condenados les sea impuesta dicha penalidad. Algo similar ocurre en el Código Penal francés, donde se implanta esta tipología correctora como una de las posibles penas a imponer a las personas físicas. Finalmente, cabe mencionar lo ocurrido en Inglaterra y Gales, donde la Criminal Justice Act 2003 destaca la existencia de la cadena perpetua (life) para determinados criminales, estableciéndose concretamente para aquellas situaciones impuestas de forma obligatoria por la ley (Mandatory life sentence) y en los casos de reiteración de acciones delictivas (Life sentence for second listed

1 MORILlAS CUEVA, L., "Reflexiones sobre el derecho penal del futuro", en Revista Electrónica de Ciencia Penal y Criminología, vol. 04-06, 2002, págs. 1-23.

2 MAPELLI CAFFARENA, B., Las consecuencias jurídicas del delito. Navarra, 2005, pág.19. 
offence). En este sentido, Roig Torres establece que "la única verdaderamente preceptiva es la Mandatory life sentence, para las conductas de asesinato"3.

\section{BREVE REFERENCIA HISTÓRICA}

La instauración de las penas perpetuas no se debería considerar como una novedad dentro de los textos legales españoles, ya que, en anteriores Códigos Penales, entre otros muchos tipos de condena, aparece una clara alusión a aquellas represiones que se podrían englobar dentro de esta tipología punitiva.

\subsection{Código Penal de 1822}

En atención al momento histórico en el que se redactó el Código Penal de 1822, González Collantes afirma que "debe tenerse en cuenta que, así como los ilustrados, o muchos de ellos, se opusieron a la pena capital, defendieron la de privación de libertad de por vida"4.

En este sentido, en el Código Penal de 1822 ya se hacía referencia a las mismas, ya que, como se puede apreciar en la descripción de los siguientes artículos, la aplicación de estas condenas era habitual. Así, el artículo 28 del mencionado texto legal establecía que, entre otras posibles condenas, los delincuentes podrían ser castigados con la pena de trabajos perpetuos: "a ningún delito, ni por ningunas circunstancias, excepto en los casos reservados a los fueros eclesiástico y militar, se aplicarán en España otras penas que las siguientes. Penas corporales. Primera. La de muerte. Segunda. La de trabajos perpetuos. Tercera. La de deportación. Cuarta. La de destierro o extrañamiento perpetuo del territorio español. Quinta. La de obras públicas. Sexta. La de presidio. Séptima. La de reclusión en una casa de trabajo. Octava. La de ver ejecutar una sentencia de muerte. Novena. La de prisión en una fortaleza. Décima. La de confinamiento en un pueblo o distrito determinado. Undécima. La de destierro perpetuo o temporal de un pueblo o distrito determinado".

Por otro lado, en el artículo 47 de dicho Código Penal se produce la ejecución de dicha medida punitiva, estableciéndose en el mismo la gravedad que suponía la imposición de esta condena: "los reos condenados a trabajos perpetuos serán conducidos al establecimiento más inmediato de esta clase, y en él estarán siempre y absolutamente separados de cualesquiera otros. Constantemente llevarán una cadena que no les impida trabajar, bien unidos de dos en dos, bien arrastrando cada uno la suya. Los trabajos en que se ocupen estos delincuentes serán los más duros y penosos; y nadie podrá dispensárselos sino en el caso de enfermedad, ni se les permitirá más descanso que el preciso".

No obstante, dentro del articulado del mencionado texto legal también se hacía referencia a la posible suspensión de la pena de trabajos perpetuos, pero para ello, según se establece en el artículo 144, el interno debe mostrarse arrepentido por el delito cometido, siendo permutada dicha condena por la de deportación: "Por medio del arrepentimiento y de la enmienda el condenado a trabajos perpetuos, podrá, después de estar en ellos diez años, pasar a la deportación”.

3 ROIG TORRES, M., La cadena perpetua en el derecho alemán y británico. La prisión permanente revisable, Madrid, 2016, pág. 70.

4 GONZÁLEZ COLLANTES, T., "Las penas de encierro perpetuo desde una perspectiva histórica", en Foro, Nueva época, vol. 18, 2015, págs. 51-91. 
Finalmente, en referencia a las personas mayores de setenta años que habían sido condenados a trabajos perpetuos por la comisión de algún tipo de acción delictiva, el artículo 66 del Código Penal de 1822 afirmaba que dichos delincuentes estarían destinados a la reclusión por el resto de sus vidas, hecho que se podría considerar como un adelanto de la cadena perpetua, la cual aparecía de forma detallada en el texto legal de 1848 .

\subsection{Código Penal de 1848}

Como ya se ha mencionado anteriormente, fue con la redacción del Código Penal de 1848 cuando se instauró la privación de libertad permanente en España. Así, en el artículo 24, dentro de las penas aflictivas, las cuales estaban transcritas de mayor a menor gravedad, entre otro tipo de condenas, se hacía referencia a la cadena perpetua y a la reclusión perpetua.

Dentro del mencionado texto legal, existen diversos preceptos que hacen una referencia expresa a dicha pena de prisión, destacando, por ejemplo, lo descrito en el artículo 96, el cual señala que "los sentenciados a cadena temporal o perpetua trabajarán en beneficio del Estado; llevarán siempre una cadena al pie pendiente de la cintura, o asida a la de otro penado: se emplearán en trabajos duros y penosos, y no recibirán auxilio alguno fuera del establecimiento. Sin embargo, cuando el Tribunal, consultando la edad, salud, estado o cualesquiera otras circunstancias personales del delincuente, creyere que este debe sufrir la pena en trabajos interiores del establecimiento, lo expresará así en la sentencia".

En referencia a las personas mayores de sesenta años, así como a las mujeres a las que se les imponía una cadena perpetua, el Código Penal de 1848 establecía que ambos colectivos deberían ser trasladados a una casa de presidio mayor, donde siempre estarían cumpliendo dicha condena con internos o internas de su mismo sexo.

Finalmente, cabe destacar lo descrito en el artículo 100, el cual se centraba en puntualizar lo relativo a la reclusión perpetua, la cual se podía considerar que presentaba una menor gravedad y que se centraba en la aplicación de trabajos forzosos a los internos, siendo estos realizados, necesariamente, dentro del centro penitenciario. Así, dicho precepto disponía que "la reclusión perpetua se sufrirá en un establecimiento situado dentro o fuera de la Península, y en todo caso lejano al domicilio del penado. Todos los condenados a esta pena están sujetos a trabajos forzoso en beneficio del Estado dentro del recinto del establecimiento. El trabajo, disciplina, traje y régimen alimenticio serán uniformes".

Cervelló Donderis destaca que dicho Código Penal tuvo una gran aceptación por parte de la doctrina jurídica de aquella época, ya que presentaba una gran estructura y la rigurosidad del mismo se mostraba en consonancia con el Estado liberal, el cual lo utilizaba como herramienta de represión para defender el orden social ${ }^{5}$.

\subsection{Código Penal de 1870}

Este texto legal, el cual continuó en vigor hasta finales de la década de los años veinte del posterior siglo, pero que, por diferentes motivos, volvió a resurgir hasta ser suprimido totalmente a principios de la década de los treinta, fue el último que hace referencia expresa

5 CERVELLÓ DONDERIS, V., Prisión perpetua y de larga duración. Régimen jurídico de la prisión permanente revisable, Valencia, 2016, pág. 47. 
a la cadena perpetua, ya que en los siguientes Códigos Penales se fijaría un límite máximo de tiempo para que los reclusos pudieran salir en libertad.

Una de las principales novedades instauradas en este Código Penal fue la inclusión del indulto a aquellos internos que hubiesen sido condenados con la cadena perpetua, siempre que no se observase un grave comportamiento, acontecimiento que podría revocar dicha medida, pasando a cumplir el delincuente la pena a perpetuidad. Así, el artículo 29 establecía que "los condenados a las penas de cadena, reclusión y relegación perpetuas y a la de extrañamiento perpetuo serán indultados a los treinta años de cumplimiento de la condena, a no ser que por su conducta o por otras circunstancias graves, no fuesen dignos del indulto, a juicio del Gobierno".

En los artículos 106, en el cual se detallan los territorios donde se podía cumplir esta pena de prisión, 107, donde se puntualizan las particularidades de la misma, y 109, en el que se especifican las singularidades de los internos con sesenta años. En este sentido, el primero de los mencionados preceptos decía que "la pena de cadena perpetua se cumplirá en cualquiera de los puntos destinados a este objeto, en África, Canarias o Ultramar". Posteriormente, el siguiente artículo exponía que "los sentenciados a cadena temporal o perpetua trabajarán en beneficio del Estado; llevarán siempre una cadena al pie, pendiente de la cintura; se emplearán en trabajos duros y penosos, y no recibirán auxilio alguno de fuera del establecimiento. Sin embargo, cuando el Tribunal, consultando la edad, salud, estado o cualesquiera otras circunstancias personales del delincuente, creyere que debe sufrir la pena de trabajos interiores del establecimiento, lo expresará así en la sentencia". Finalmente, en el 109 se señalaba que "el condenado a cadena temporal o perpetua que tuviere antes de la sentencia sesenta años de edad, cumplirá la condena en una casa de presidio mayor. Si los cumpliere estando ya sentenciado, se le trasladará a dicha casa-presidio, en la que permanecerá durante el tiempo prefijado en la sentencia".

En este sentido, Cuerda Riezu, a tenor de los artículos descritos anteriormente, considera que dicho concepto de perpetuidad lleva aparejado una serie de singularidades que hacen que se pueda poner en duda dicha afirmación. Así, dicho autor detalla que "en primer lugar, porque el artículo 29 del Código Penal de 1870 preveía el indulto, salvo excepciones, a los 30 años; y, en segundo lugar, muchos de los preceptos relativos a las penas privativas de libertad eran letra muerta" ${ }^{\circ}$.

\subsection{Código Penal de 1928}

Este texto entró en vigor con la intención de eliminar por completo determinados preceptos del código anterior. No obstante, el recorrido del mismo no fue muy prolongado, ya que a principios de 1931 se decidió proceder a la derogación del mismo, entrando en vigor nuevamente el ya extinto de 1870, a la espera de la redacción de un nuevo compendio legal, el cual tuvo lugar en 1932.

Como ya se ha mencionado anteriormente, con la redacción de este nuevo código se suprimió por completo todos aquellos artículos que hacían referencia a la condena por perpetuidad en todos sus ámbitos. En este sentido, se procedió a la sustitución de la cadena perpetua por el establecimiento de una horquilla temporal donde se fijaba un límite

6 CUERDA RIEZU, A., Cadena perpetua y las penas muy largas de prisión: Por qué son inconstitucionales en España, Barcelona, 2011, pág. 18. 
mínimo y máximo para el cumplimiento de la pena de prisión, el cual iba desde los dos meses y un día hasta los treinta años.

Dicha afirmación aparece reflejada en el artículo 108 del citado Código, precepto que versaba sobre la extensión de las penas y sus efectos, y en el que se reflejaba lo siguiente: "La extensión de las penas establecidas en éste Código será la siguiente: Las de reclusión y prisión, de dos meses y un día a treinta años. La de deportación, de seis a treinta años. Las de confinamiento, destierro e inhabilitación absoluta o especial, de dos meses y un día a treinta años. La de arresto, de un día a dos meses. La pena de multa consistirá en el pago de 1 a 100.000 pesetas, salvo el caso en que se fije para multa una cantidad que sea producto de multiplicar o cociente de dividir por otra determinada y no se ordene expresamente el límite".

Por otro lado, en relación a las penas que se les podía imponer a los internos condenados bajo el conglomerado de preceptos descritos en este texto legal, el artículo 87 establece las siguientes: muerte; reclusión; prisión, deportación; confinamiento; destierro; inhabilitación absoluta o especial para cargos públicos, profesión arte, oficio y derechos políticos; arresto, y multa. Como se puede apreciar, desaparecía así toda referencia expresa a la cadena perpetua, la cual sí venía reflejada en los Códigos anteriores.

No obstante, conviene destacar que este Código encerraba una serie de cláusulas donde se especificaba que aquellos internos que eran considerados incorregibles pudieran llegar a cumplir condenas durante un período de tiempo indeterminado. Así aparece reflejado en el artículo 157, en el que se establecía que "se ordenará que permanezca en un establecimiento o departamento destinado a incorregibles, por tiempo indeterminado". En este sentido, Cámara Arroyo y Fernández Bermejo consideran que dicho acontecimiento jurídico podría llegar a ser considerado como un antecedente de las medidas de seguridad que se imponen hoy día?

\subsection{Código Penal de 1932}

A principios de los años treinta, debido al fracaso del texto legal publicado en 1928, se redacta un nuevo Código Penal, el cual, además de mantener la supresión de la cadena perpetua, introdujo la eliminación de la pena de muerte, estableciéndose el límite máximo de los treinta años como la sanción más gravosa que se podía imponer a los internos en los centros penitenciarios de aquella época. Dicha afirmación aparece reflejada en el artículo 36, el cual establece que "la pena de reclusión mayor durará de veinte años y un día a treinta años".

A tenor de lo descrito anteriormente en lo relacionado con el texto de 1928, se podría afirmar que verdaderamente la supresión definitiva de la cadena perpetua tuvo lugar con la publicación del compendio de 1932, ya que el anterior, el divulgado en 1928, fue suprimido y sustituido nuevamente por el de 1870, a la espera de un nuevo Código Penal. Así, en la Exposición de Motivos de esta última compilación aparece reflejado que, entre otras reformas, "se tiende a humanizar el Código, y para lograrlo se deroga la pena de muerte y las perpetuas".

7 CÁMARA ARROYO, S., y FERNÁNDEZ BERMEJO, D., La prisión permanente revisable: el ocaso del humanitarismo penal y penitenciario, 2016, pág. 42. 
En este sentido, Beccaria, entre otras afirmaciones de gran relevancia dentro del Derecho Penal y de la Criminología, declaró que la humanización del sistema legal era necesario, ya que las penas especialmente gravosas no son útiles para el interno ni para el resto de la sociedad, estableciendo que "el fin, pues, no es otro que impedir al reo causar nuevos daños a sus ciudadanos y retraher a los demás de la comisión de otros iguales. Luego deberán ser escogidas aquellas penas y aquel método de imponerlas que, guardada la proporción, hagan una impresión más eficaz y más durable sobre los ánimos de hombres, y la menos dolorosa sobre el cuerpo del reo"s.

Este Código Penal convivió durante más de una década con la Ley de Vagos y Maleantes, la cual fue aprobada en agosto de 1933, siendo derogada y sustituida en 1970 por el régimen franquista. En dicha norma se establecía la imposición de medidas de seguridad privativas de libertad a determinados sujetos, debiendo ser cumplidas inmediatamente después de la extinción de las penas impuestas previamente por el delito o delitos cometidos. Así, en el artículo 4 se aprecia cómo, a pesar de establecer una duración indeterminada para dicha sanción, afirma que la misma no podrá ser inferior al año, ni superar los cinco años.

En atención a las afirmaciones realizadas, y teniendo en cuenta lo puntualizado en este Código y en la mencionada Ley, a aquellos internos que les fuese impuesta una condena de treinta años de prisión, y posteriormente una medida de seguridad en su límite máximo, podrían pasar a estar condenados a privación de libertad para el resto de sus vidas, dependiendo de la edad de los mismos, ya que el cumplimiento total pasaría a ser de treinta y cinco años.

\subsection{Código Penal de 1944}

Tras la victoria del bando sublevado en la Guerra Civil española, el régimen franquista consideró necesario la implantación de un nuevo Código Penal que se adaptara en mayor medida a las pretensiones que su sistema dictatorial quería imponer en la sociedad. Así, dejando atrás el texto legal redactado durante el establecimiento de la Segunda República en nuestro país, en 1944 se publicó un nuevo compendio punitivo que endureció nuevamente la imposición de las sanciones ante la comisión de determinadas infracciones. En este sentido, Andrés Laso establece que las muestras de severidad aparecían reflejadas en "la apreciación obligatoria de las agravantes por parte del juzgador, antes voluntaria; la imposición de una pena notablemente más grave a partir de la segunda reincidencia; la creación de dos nuevas agravantes de publicidad y de lugar sagrado; el castigo en todo caso de los actos preparatorios de proposición, conspiración y provocación para delinquir; la previsión de nuevos delitos cualificados por el resultado, etc."10.

Tras la abolición de la pena de muerte y la condena a perpetuidad llevadas a cabo por el anterior Código Penal, tras la redacción del fechado en 1944 se produjo la recuperación del correctivo más gravoso que se le puede imponer a una persona, es decir, la pena capital, dejando fuera del articulado de dicho compendio legal todo lo referente a la cadena perpetua.

8 BECCARIA, C., Tratado de los delitos y de las penas, Madrid, 2015, pág. 34.

9 GONZÁLEZ COLLANTES, T., "Las penas de encierro perpetuo... cit., pág. 68.

10 ANDRÉS LASO, A., "Legislación penal, procesal penal y penitenciaria tras la guerra civil española", en Revista Jurídica de Castilla y León, 2015, págs. 1-44. 
En consecuencia, en el artículo 27 del Código Penal de 1944, el cual está referido a la clasificación de las penas, se puede apreciar como una de las posibles condenas a imponer es la muerte del interno. Por otro lado, en el artículo 83, en referencia al cumplimiento de las mismas, el texto establece que "la pena de muerte se ejecutará en la forma determinada por los Reglamentos. No se ejecutará esta pena en la mujer que se halle encinta, ni se le notificará la sentencia en que se le imponga, hasta que hayan pasado cuarenta días después del alumbramiento".

No obstante, cabe resaltar que, al igual que ocurría en el Código de 1932, la condena máxima de prisión que se le podía imputar a los prisioneros en aquellas décadas, a excepción de la ya referida pena capital, era de treinta años. Por consiguiente, en referencia a la duración de los castigos a imponer, el artículo 30 del texto legal publicado en 1944 establecía que "la pena de reclusión mayor durará de veinte años y un día a treinta años".

A pesar de lo descrito anteriormente, resulta conveniente matizar que entre el articulado de dicho compendio se aprecia como existe la posibilidad de aplicar una condena de mayor duración a la ya mencionada. Dicha afirmación viene reflejada en el artículo 75 , donde se remarca que "en los casos en que la Ley señala una pena superior a otra determinada sin designar especialmente cuál sea, si no hubiere pena superior en la escala respectiva, o aquella fuese la de muerte, se considerarán superiores las siguientes: $1^{\mathrm{a}}$. Si la pena determinada fuese la de reclusión mayor, la misma pena, con la cláusula de que su duración será de cuarenta años".

Finalmente, cabe destacar que el mencionado compendio legal fue testigo de diversas reformas, así como de la publicación de un texto revisado en 1963 y de un texto refundido en 1973. Posteriormente, después de numerosos retoques, se procedió a la publicación del Código Penal de 1995, el cual se configuraba como un nuevo texto que se ajustaba con mayor profundidad a la situación política que se estaba viviendo en España.

\subsection{Código Penal de 1995}

Con la entrada en vigor de dicha Ley se pretendía conceder una incuestionable universalidad y generalidad a la misma, implementado cierta ordenación dentro de la potestad punitiva del Estado, estando reflejadas estas características dentro de la Exposición de Motivos del nuevo Código, donde se aprecia que "el presente proyecto difiere de los anteriores en la pretensión de universalidad. Se venía operando con la idea de que el Código Penal constituyese una regulación completa del poder punitivo del Estado. La realización de esa idea partía ya de un déficit, dada la importancia que en nuestro país reviste la potestad sancionadora de la Administración; pero, además, resultaba innecesaria y perturbadora".

La importancia de la adaptación del nuevo Código a la realidad social, jurídica y política de la colectividad española es innegable, ya que tras la Constitución Española de 1978 se hacía necesaria una reformulación de determinados artículos que se encontraban desfasados. No obstante, a lo largo de estos años, se han llevado a cabo más de una treintena de modificaciones, las cuales, entre otros acontecimientos de suma importancia, han servido para robustecer el sistema punitivo que aparecía reflejado en dicho compendio desde su publicación. Así, en palabras de Casals Fernández, se puede atestiguar que "la 
tendencia reformadora va encaminada hacia un continuo endurecimiento de las penas privativas de libertad y hacia un debilitamiento de las garantías jurídicas"11.

Sin duda, a pesar de las numerosas reformas acontecidas, la modificación más relevante fue la llevada a cabo por la Ley Orgánica 1/2015, de 30 de marzo, donde se reintroduce en nuestro sistema punitivo una especie de castigo a perpetuidad, pero con determinados matices. En este sentido, Pascual Matellán establece que, por un lado, esta condena de por vida "se pretende introducir en la legislación penal española bajo la denominación de prisión permanente revisable"; $y$, por otro, afirma que no resulta inédita para nuestro sistema penal, ya que "no estamos ante una pena desconocida en nuestra historia legislativa, pero sí ante una pena lejana, ya que no se introdujo en ninguna de las codificaciones penales instauradas durante el s. XX" ${ }^{12}$.

Así, tras las reformas operadas en el mencionado Código Penal, dicha Ley Orgánica introduce entre su articulado diferentes referencias a la prisión permanente revisable, apareciendo reflejada, por ejemplo, en el artículo 35, donde se describen las penas privativas de libertad: "son penas privativas de libertad la prisión permanente revisable, la prisión, la localización permanente y la responsabilidad personal subsidiaria por impago de multa".

Finalmente, cabe mencionar que en el Preámbulo de la Ley Orgánica 1/2015, de 30 de marzo, se describe, teniendo en cuenta la trascendencia social que originaban determinados hechos delictivos, la obligación de establecer este tipo de privación de libertad. Así, se afirma que "la necesidad de fortalecer la confianza en la Administración de Justicia hace preciso poner a su disposición un sistema legal que garantice resoluciones judiciales previsibles que, además, sean percibidas en la sociedad como justas. Con esta finalidad, siguiendo el modelo de otros países de nuestro entorno europeo, se introduce la prisión permanente revisable para aquellos delitos de extrema gravedad, en los que los ciudadanos demandaban una pena proporcional al hecho cometido".

\section{CONFIGURACIÓN DE LA PRISIÓN PERMANENTE REVISABLE}

\subsection{Manifestaciones a favor o en contra de la prisión permanente revisable}

Desde sus inicios, esta pena privativa de libertad ha sido testigo de muchas críticas dentro de la doctrina jurídica, manifestando su desagrado por considerar innecesaria su implantación dentro del articulado existente en el Código Penal español. En este sentido, Ríos Martín afirma que "la prisión perpetua revisable es inconstitucional porque atenta contra la dignidad de los seres humanos — art. $10 \mathrm{CE}$ - ; contra la prohibición de penas inhumanas y tratos inhumanos y degradantes - art. $15 \mathrm{CE}$ - contra el mandato de la orientación de las penas hacia la reeducación y reinserción social art. $25 \mathrm{CE}$; además, su indeterminación se enfrenta abiertamente al principio básico de seguridad jurídica" ${ }^{13}$. Siguiendo este hilo

11 CASALS FERNÁNDEZ, A., La prisión permanente revisable, Madrid, 2019, pág. 55.

12 PASCUAL MATELLÁN, L., "La prisión permanente revisable. Un acercamiento a un derecho penal deshumanizado", en Clivatge. Estudis i testimonis sobre el conflicte i el canvi socials, 2015, págs. 51-65.

13 RÍOS MARTÍN, J.C., "La pena de prisión permanente revisable. La suspensión y sustitución de las penas", en Cuadernos penales. José María Lidón, vol. 10, 2014, págs. 21-62. 
argumental, Gimbernat Ordeig manifiesta que "un encarcelamiento en estas condiciones, que sólo puede tener como consecuencia el aniquilamiento físico y moral del recluso, es impropio de un Estado social de Derecho, atenta contra la dignidad humana, el fin resocializador de las penas y la prohibición de tratos inhumanos, y hace todo lo contrario de lo que prescriben las recomendaciones del Consejo de Ministros europeo"14.

Acale Sánchez se muestra muy crítica con la imposición por parte del legislador de este tipo de sanción, estableciendo una comparativa del sistema penal vigente con un cadalso, siendo esta una estructura arquitectónica que se utilizaba antiguamente para la ejecución pública de los criminales. En este sentido, dicha autora afirma que "la prisión permanente revisable es una pena porque se impone por parte del legislador para el autor de los delitos -supuestamente- más graves, y con ella se pretende castigarlo por el daño que ha infringido a la sociedad en su conjunto y a la concreta víctima de su delito. Ahora bien, su ejecución se ha previsto de tal forma, que más que estar orientada proactivamente a alcanzar la reeducación y la reinserción social del delincuente, lo único que persigue es convertir en espectáculo la propia ejecución de la pena, sobre el cadalso del nuevo sistema penal"15.

López Peregrín también se muestra contraria a dicha pena de prisión, considerando, al igual que los investigadores señalados anteriormente, que la imposición de la misma infringe un gran golpe a la dignidad de las personas, imposibilitándole la oportunidad de modificar su conducta y adentrarse en la sociedad como un sujeto resocializado y reeducado. Así, dicha autora declara que "si la regulación niega total y absolutamente que el sujeto pueda llegar a ser liberado, la pena sería contraria a la prohibición de malos tratos, inhumanos y degradantes, ya que negar incondicionalmente toda expectativa de liberación supone negar al sujeto, a priori y absolutamente, su capacidad de cambio: tratar así a un ser humano es inhumano y atenta directamente contra su dignidad"16.

En referencia a la posible inconstitucionalidad de dicha condena, Serrano Gómez y Serrano Maíllo, a pesar de manifestar la derogación de la misma, declaran que no debería ser considerada como tal, ya que, entre otros motivos, especifican que el hecho de presentarse como una pena revisable hace que la consideración de la misma conlleve la no existencia de un trato inhumano o degradante ${ }^{17}$.

En este sentido, a tenor de lo descrito por estos autores, se podría considerar que la introducción de la prisión permanente revisable no se muestra contraria a lo impuesto en el artículo 15 de la Constitución Española, en el que se establece que "todos tienen derecho a la vida y a la integridad física y moral, sin que, en ningún caso, puedan ser sometidas a tortura ni a penas o tratos inhumanos o degradantes". Por otro lado, el artículo 25.2 tampoco se vería afectado por la misma, ya que el contenido de dicha sanción prevé la posibilidad, teniendo en cuenta una diversidad de requisitos, de que los internos a los que se le ha impuesto dicha condena puedan acceder a la aplicación de determinados beneficios penitenciarios.

14 GIMBERNAT ORDEIG, E., "Contra la prisión permanente revisable", en Anuario de derecho penal y ciencias penales, vol. 71, 2018, págs. 491-498.

15 ACALE SÁNCHEZ, M., La prisión permanente revisable: ¿pena o cadalso?, Madrid, 2016, pág. 215.

16 LÓPEZ PEREGRÍN, C., "Más motivos para derogar la prisión permanente revisable", en Revista Electrónica de Ciencia Penal y Criminología, 2018, págs. 1-49.

17 SERRANO GÓMEZ, A., y SERRANO MAÍLLO, I., Constitucionalidad de la prisión permanente revisable y razones para su derogación, Madrid, 2016, pág. 30. 
En consecuencia, también existen voces dentro de la doctrina jurídica que se muestran a favor de la imposición de la prisión permanente revisable en nuestro Código Penal. Así, por ejemplo, Manzanares Samaniego, miembro permanente del Consejo de Estado, se muestra partidario de la misma, ya que considera que, al igual que así la tienen reconocida en sus respectivas normas legales determinados países de nuestro entorno político-económico más cercano, su implantación en nuestro ordenamiento jurídico resulta fundamental ${ }^{18}$.

En este mismo contexto doctrinal se encuentran Jaén Vallejo y Perrino Pérez, quienes se muestran a favor de la imposición de dicha condena, considerándola necesaria para determinadas infracciones de extrema gravedad, manifestando que la legitimidad de la misma es similar a la que presentan diversas sanciones en las que se aprecia un extenso período de tiempo en lo que referido al cumplimiento de las mismas. Así, dichos autores declaran que "una pena de prisión permanente revisable para determinados supuestos delictivos de extrema gravedad, como terrorismo con resultado de muerte, asesinatos especialmente reprobables, como ocurre en el caso de determinadas agresiones a menores, atentando a su indemnidad sexual y su vida, etc., que es la regla general en los países de la Unión Europea, en los que en su gran mayoría está implantada la prisión perpetua desde hace tiempo, es tan legítima como un pena de privación de libertad de larga duración"19.

Finalmente, Cuello Contreras y Mapelli Caffarena opinan que "en su regulación se ha sido tan restrictivo - ha pesado más lo de revisable, que lo permanente-, que no es difícil imaginar condenados a penas de prisión que terminen pasando más tiempo en la cárcel que si lo hubieran sido a la PPR. Con estas condiciones parece difícil sostener la inconstitucionalidad de la PPR, incluso el propio Estatuto de Roma de la CPI, que ha tenido en cuenta nuestro legislador, reconoce expresamente esta pena siempre que se revise a los veinticinco años" ${ }^{\prime 20}$.

\subsection{Incidencia de la prisión permanente revisable dentro de la normativa penitenciaria}

La legislación que rige dentro de las prisiones tiene su punto de partida en el desarrollo de la Ley Orgánica 1/1979, de 26 de septiembre, General Penitenciaria (en adelante, LOGP), la cual se configura como la primera ley de estas características que se aprobó una vez decretada la democracia en nuestro país. Por otro lado, y no por ello carece de menor importancia, tuvimos que esperar más de quince años hasta la entrada en vigor del Reglamento que regula dicha ley, estando regulado en el Real Decreto 190/1996, de 9 de febrero.

Desde su entrada en vigor, la LOGP ha sufrido leves modificaciones, como así lo certifica De Vicente Martínez, quien afirma que "las escasas reformas no han supuesto más que leves retoques"21. En este sentido, dado a los más de cuarenta años de dicha ley,

18 MANZANARES SAMANIEGO, J.L., "Las penas en la Ley Orgánica 1/2015, de 30 de marzo”, en La Ley Penal, 2782/2015.

19 JAÉN VALLEJO, M., y PERRINO PÉREZ, A.L., La reforma penal de 2015. (Análisis de las principales reformas introducidas en el Código Penal por las Leyes Orgánicas 1 y 2/2015, de 30 de marzo), Madrid, 2015, pág. 32.

20 CUEllo CONTRERAS, J., y MAPELli CAFFARENA, B., Curso de Derecho Penal. Parte General, Madrid, 2015, p. 268.

21 DE VICENTE MARTÍNEZ, R., "La Ley Orgánica General Penitenciaria 40 años después", en Anuario de derecho penal y ciencias penales, vol. LXXII, 2019, págs. 127-153. 
se podría establecer la necesidad de proceder a un examen en profundidad de la misma, ya que los tiempos cambian y existe una evolución delictiva y tratamental de los sujetos merecedores de su entrada en un centro penitenciario. Así, se podría afirmar que un claro ejemplo de ello sería la inclusión de la pena de prisión permanente revisable en la reforma del Código Penal llevada a cabo en 2015, configurándose como un claro factor diferencial de los presos condenados con esta medida del resto de internos.

Actualmente, el modelo penitenciario español se rige por el sistema de individualización científica, hecho que viene reflejado en el artículo 72.3 y 4, donde se esclarece que "siempre que de la observación y clasificación correspondiente de un interno resulte estar en condiciones para ello, podrá ser situado inicialmente en grado superior, salvo el de libertad condicional, sin tener que pasar directamente por los que le preceden" y, por otro lado, se afirma que "en ningún caso se mantendrá a un interno en un grado inferior cuando por la evolución de su tratamiento se haga merecedor a su progresión". Dichos preceptos, entre otras características, manifiestan el fin de un método penal progresivo, siendo este el que regía en nuestras prisiones y por el cual los internos para poder disfrutar de la libertad definitiva o, incluso, de la condicional, tenían que pasar por los diferentes grados de tratamiento.

En referencia a dicho modelo penitenciario gradual, Fernández Bermejo, en un artículo escrito para conmemorar el cuarenta aniversario de la entrada en vigor de la LOGP, dispone que "han transcurrido ciento dieciocho años desde que se instauró en España, de forma generalizada y con reconocimiento legal, el sistema progresivo de cumplimiento de condenas" 22 .

En referencia al sistema de individualización científica, el principio de flexibilidad es uno de sus mayores valedores, ya que ha permitido establecer una amplia variedad de mejoras para que el interno pueda reeducarse y, por otro lado, reinsertarse en la sociedad. Así, dicho precepto aparece regulado en el artículo 100.2 del Reglamento Penitenciario dispone que "con el fin de hacer el sistema más flexible, el Equipo Técnico podrá proponer a la Junta de Tratamiento que, respecto de cada penado, se adopte un modelo de ejecución en el que puedan combinarse aspectos característicos de cada uno de los mencionados grados, siempre y cuando dicha medida se fundamente en un programa específico de tratamiento que de otra forma no pueda ser ejecutado".

En consecuencia, y haciendo especial hincapié en la importancia que tuvo su introducción en la legislación penitenciaria, Sanz Delgado apunta que "el artículo 100.2 del Reglamento Penitenciario se ha convertido en el verdadero reflejo del artículo 72 de la Ley Orgánica General Penitenciaria, en el contenido relativo a la individualización científica y, por ende, en una modalidad expansiva de lo dispuesto en el artículo 25.2 de la Constitución Española"23.

En este sentido, y en contraprestación a la finalidad del principio de flexibilidad, es decir, a la consecución de la reeducación y de la reinserción social, la prisión permanente

22 FERNÁNDEZ BERMEJO, D., "Del sistema progresivo a la individualización científica. La elaboración de la Ley General Penitenciaria y la relevancia del bienio 1978-1979 en el derecho penitenciario", en Anuario de derecho penal y ciencias penales, vol. LXXII, 2019, págs. 483-519.

23 SANZ DELGADO, E., "El trabajo penitenciario y el principio de flexibilidad”, en García Valdés, C., Valle Mariscal de Gante, M., Cuerda Riezu, A.R., Martínez Escamilla, M., y Alcácer Guirao, R., (Coords.), Estudios penales en homenaje a Enrique Gimbernat, vol. 2., Madrid, 2008, pág. 2423. 
revisable conlleva una apreciable problemática en lo que respecta a tales fines, ya que el hecho de estar condenados a este tipo de condena no beneficia la obtención de tales éxitos penitenciarios.

Por otro lado, en lo que respecta a los permisos de salida, y entendiendo como tales, en referencia a los ordinarios o comunes, aquellas autorizaciones previstas para que los internos puedan comenzar a preparar su futura vida en libertad, siendo estos de gran ayuda dentro de los diferentes programas tratamentales. Así, Casals Fernández señala que "el Código Penal ha debido de indicar un plazo específico, ya que al carecer de límite temporal concreto de esta pena no sería posible realizar el cálculo para conceder permisos de salida. Dispone el artículo 36.1 que los condenados a pena de prisión permanente revisable no podrán disfrutar de permisos de salida hasta que no hayan cumplido un mínimo de ocho años, salvo en delitos referentes a organizaciones y grupos terroristas y delitos de terrorismo que deberán haber cumplido un mínimo de doce años. Hay que recordar que el permiso de salida no es un premio o recompensa sino un derecho del interno integrado en el tratamiento penitenciario orientado a la reinserción social" ${ }^{24}$. En atención a la mencionada afirmación, se puede apreciar como existe una dificultad real para aquellos sujetos condenados por la pena de prisión permanente revisable de conseguir los fines que persigue la pena, es decir, la reeducación y la reinserción social.

Finalmente, en relación con los beneficios penitenciarios, los cuales se configuran como un derecho inserto dentro del Reglamento Penitenciario, la legislación estatal estipula que será el adelantamiento de la libertad condicional, clasificados en tercer grado, entre otras circunstancias, y el indulto particular, el cual reúne una serie de particularidades propias. Así, teniendo en cuenta lo descrito anteriormente referido a la prisión permanente revisable, se podría afirmar que el disfrute de los mismos lleva aparejada una dificultad extrema. En este sentido, Gálvez Jiménez afirma que "con la prisión permanente revisable el penado puede llegar a cumplir treinta y cinco años de cumplimiento efectivo sin casi opciones de poder obtener beneficios penitenciarios" 25 .

\subsection{Aplicabilidad de la prisión permanente revisable en el Código Penal}

En referencia a la mencionada condena, la legislación punible vigente establece una serie de requisitos para la determinación de la misma. En este sentido, el término "revisable" es el que puede levantar una mayor controversia a la hora de determinar la permanencia del interno dentro de prisión. En consecuencia, el artículo 36, en lo referido a la revisión que se ha de hacer de dicha pena, nos remite directamente a lo descrito en el artículo 92 de nuestro Código, donde aparecen expuestas una serie de exigencias para proceder a un minucioso examen, lo que podría desembocar en la consecución de la libertad condicional o, incluso, en la suspensión de la condena.

Así, el mencionado precepto establece que, para proceder al análisis de la misma, el penado debe de:

24 CASALS FERNÁNDEZ, A., "La ejecución penitenciaria de la pena de prisión permanente revisable", en Anuario de derecho penal y ciencias penales, vol. LXXII, 2019, pág. 678.

25 GÁLVEZ JIMÉNEZ, A., "La aplicación de la prisión permanente revisable ex LO 1/2015, de 1 de julio", en Revista Internacional de Doctrina y Jurisprudencia, vol. 18, 2018, págs. 1-19. 
a) Haber cumplido veinticinco años de condena.

b) Se encuentra clasificado en tercer grado.

c) Existencia de un pronóstico favorable de reinserción social.

d) En el supuesto de terroristas, además de lo anteriormente mencionado, el sujeto deberá mostrar signos inequívocos de abandono de la actividad terrorista, colaborando activamente con las autoridades.

Una vez detallados los mencionados requisitos, surge la necesidad de determinar como un interno al que le ha sido impuesta la citada condena puede llegar a estar clasificado en tercer grado. En este sentido, se presupone que los mismos tendrán que ir evolucionando favorablemente dentro de prisión hasta llegar al ansiado nivel tratamental. Siguiendo este mismo hilo argumental, Juanatey Dorado establece que "la progresión de grado tendrá lugar cuando se produzca una modificación de aquellos aspectos de la personalidad relacionados con su actividad delictiva. Dicha evolución favorable ha de manifestarse en la conducta global del interno y ha de dar lugar a un incremento de la confianza en él depositada y a la atribución de una responsabilidad cada vez mayor"26.

Por otro lado, y en referencia a la mencionada progresión de grado de aquellas personas que han sido condenadas por dos o más delitos y, en al menos una ocasión, han sido castigados con la prisión permanente revisable, el artículo 78 bis del Código Penal establece el cumplimiento de:

a) Mínimo de dieciocho años de prisión, cuando por uno de los delitos cometidos haya sido condenado con dicha pena y las restantes sanciones impuestas por el resto de infracciones sean superiores a cinco años.

b) Mínimo de veinte años de prisión, cuando se produzca una situación similar a la mencionada anteriormente y, además, la suma del resto de acciones exceda de los quince años.

c) Mínimo de veintidós años, cuando haya cometido varios delitos y en dos o más de ellos se le haya impuesto la prisión permanente o, por otro lado, dicha condena sea consecuencia de una única infracción, pero el resto de las acciones realizadas completen un total de veinticinco o más años.

A dichas circunstancias sería preciso añadir lo establecido para los casos de presos pertenecientes a grupos terroristas, en cuyo caso, la legislación penal, dentro del precepto señalado anteriormente, establece que para el acceso a dicho grado penitenciario deberán atenerse a los límites mínimos de cumplimiento, los cuales serán de veinticuatro años, para los supuestos descritos en los apartados a) y b) y de treinta y dos años para los casos señalados en la letra c).

En atención a lo descrito anteriormente, considero necesario proceder al establecimiento de un cuadro comparativo con el objeto de ayudar a conseguir una mejor interpretación de lo desarrollado en la norma.

26 JUANATEY DORADO, C., Manual de derecho penitenciario, Madrid, 2016, pág. 138. 


\begin{tabular}{|l|l|}
\hline \multicolumn{1}{|c|}{ Revisión } & \multicolumn{1}{c|}{ Tiempo mínimo } \\
\hline Supuesto general & 25 años \\
\hline Terrorismo & 25 años \\
\hline Concurso general & $\begin{array}{l}25 \text { o } 30 \text { años dependiendo de los diferentes } \\
\text { supuestos descritos en el artículo } 78 \text { bis } 2\end{array}$ \\
\hline $\begin{array}{l}\text { Concurso terrorismo y organización } \\
\text { criminal }\end{array}$ & $\begin{array}{l}28 \text { y } 35 \text { años dependiendo de los diferentes } \\
\text { supuestos descritos en el artículo } 78 \text { bis } 3\end{array}$ \\
\hline Enfermos y mayores de 70 años & Sin plazo \\
\hline
\end{tabular}

Fuente: Cervelló Donderis, $V^{27}$.

En este sentido, el Código Penal establece una serie de acciones delictivas, las cuales presentan una extrema gravedad, a las que se les podría imponer la prisión permanente revisable. En consecuencia, tales infracciones vienen recogidas en el Libro II de la mencionada normativa, detallándose, a continuación, los fundamentos más relevantes de cada uno de ellas:

a) En lo que respecta al delito de asesinato, el artículo 140 establece que se podrá imponer dicho castigo cuando: a) la víctima sea menor de dieciséis años o "persona especialmente vulnerable por razón de su edad, enfermedad o discapacidad"; b) que a la muerte del sujeto anteceda un delito contra la libertad sexual contra la mencionada víctima; $\mathrm{c}$ ) delincuente perteneciente a un grupo $\mathrm{u}$ organización criminal; d) criminal que haya cometido, al menos, tres asesinatos, con las particularidades expuestas en el artículo 78.1.b) y 78.2.b).

b) Otra infracción por la cual se impone dicho castigo es la referida a la muerte del Rey, de la Reina o del Príncipe o Princesa de España, estando recogidos dichas conductas ilícitas en el artículo 485.

c) Según el artículo 605, también serán castigados con la prisión permanente revisable aquellos sujetos que maten al Jefe de Estado de un país extranjero, así como a cualquier persona que se encuentre bajo el amparo de un Tratado internacional, hallándose todas ellas en España.

d) Posteriormente, el Código Penal vuelve a hacer referencia a dicha sanción cuando describe los delitos de genocidio, regulados en el artículo 607, castigando a sus responsables con esta condena siempre que maten, agredan sexualmente o lesionen a alguno de los miembros de los grupos sociales afectados por dichas acciones delictivas.

e) Finalmente, a aquellos infractores que hayan cometido un delito de lesa humanidad también les será impuesta esta condena con una duración indeterminada.

27 CERVELLÓ DONDERIS, V., Prisión perpetua y de larga duración... cit., pág. 214. 


\section{ANÁLISIS CRIMINOLÓGICO DE LA APLICACIÓN DE LA PRISIÓN PERMANENTE REVISABLE EN ESPAÑA}

La relación de la criminología con el estudio de la conducta desviada es un elemento propio de su ámbito de estudio. Dicha afirmación se puede apreciar en una de las definiciones más seguidas y aceptadas por parte de la doctrina criminológica, la cual fue aportada por García-Pablos de Molina, quien afirmó que se trata de una "ciencia empírica e interdisciplinaria, que se ocupa del delito, el delincuente, la víctima y el control social del comportamiento delictivo; y que trata de suministrar una información válida, asegurada, sobre la génesis y dinámica del problema criminal y sus variables; sobre los programas y estrategias de prevención eficaz del delito; y sobre las técnicas de intervención positiva en el hombre delincuente" 28 .

No obstante, se parte de la base de que la erradicación total del delito podría considerarse como una utopía, ya que las acciones delictivas han existido siempre y lo seguirán haciendo, siendo la idiosincrasia del ser humano la que nos hace cometer infracciones por diferentes circunstancias vitales, las cuales pueden ir desde la necesidad propia del sujeto delincuente, hasta la comisión del acto por mero hedonismo.

En consecuencia, desde un punto de vista criminológico, para hacer referencia a la prisión permanente revisable resulta de vital importancia proceder al análisis de ciertas variables relacionadas con dicha ciencia, siendo esencial realizar las investigaciones oportunas para esclarecer los criterios referidos a los delincuentes y a las víctimas, los cuales se configuran como el elemento fundamental de este estudio.

Así, para llevar a cabo un análisis exhaustivo de ambos criterios criminológicos, considero primordial estudiar pormenorizadamente las diferentes sentencias de las Audiencias Provinciales ${ }^{29}$ estatales en las que, a día de hoy, se ha decidido condenar al infractor con la imposición de la prisión permanente revisable.

28 GARCÍA-PABLOS DE MOLINA, A., "La aportación de la criminología”, en Eguzkilore, vol. 3, 1989, págs. 79-94.

29 Sentencia de la Audiencia Provincial de Pontevedra 42/2017, de 14 de julio [JUR\2017\198019]; Sentencia de la Audiencia Provincial de Santa Cruz de Tenerife 100/2018, de 21 de marzo [ARP $\backslash 2018 \backslash 443$ ]; Sentencia de la Audiencia Provincial de Álava 278/2018, de 25 de septiembre [ARP\2019\27]; Sentencia de la Audiencia Provincial de A Coruña 484/2018, de 16 de octubre [JUR\2018\278986]; Sentencia de la Audiencia Provincial de Guadalajara 3/2018, de 15 de noviembre [ARP\2019\86]; Sentencia de la Audiencia Provincial de Barcelona 7/2019, de 4 de marzo [ARP 2019\501]; Sentencia de la Audiencia Provincial de Almería 122/2019, de 25 de marzo; Sentencia de la Audiencia Provincial de Sevilla 6/2019, de 22 de abril [ARP\2019\743]; Sentencia de la Audiencia Provincial de Toledo 83/2019, de 25 de abril [JUR\2019\218919]; Sentencia de la Audiencia Provincial de Valladolid 137/2019, de 4 de junio [JUR $2019 \backslash 178530$ ]; Sentencia de la Audiencia Provincial de Almería 379/2019, de 30 de septiembre [ARP\2020\348]; Sentencia de la Audiencia Provincial de Madrid 628/2019, de 30 de octubre [ARP \2020\130]; Sentencia de la Audiencia Provincial de A Coruña 197/2019, de 17 de diciembre [JUR\2020\90464]; Sentencia de la Audiencia Provincial de Vizcaya 79/2019, de 23 de diciembre [ARP $\backslash 2020 \backslash 368$ ]; Sentencia de la Audiencia Provincial de Santa Cruz de Tenerife 42/2020, de 14 de febrero [ARP $\backslash 2020 \backslash 950$ ]; Sentencia de la Audiencia Provincial de Valencia 287/2020, de 31 de julio [JUR\2020\239110]; Sentencia de la Audiencia Provincial de Alicante 526/2020, de 28 de septiembre [JUR $2020 \backslash 285611$ ]; Sentencia de la Audiencia Provincial de Huesca 97/2020, de 6 de octubre [JUR\2020\356603]; Sentencia de la Audiencia Provincial de Alicante 6/2020, de 25 de noviembre [JUR\2020\345117]; Sentencia de la Audiencia Provincial de Teruel 38/2021, de 27 de abril [JUR\2021\269513]; Sentencia de la Audiencia Provincial de Asturias 16/2021, de 26 de mayo [JUR\2021\198025]; Sentencia de la Audiencia Provincial de Barcelona 22/2021, de 8 de junio [JUR\2021\209295]; Sentencia de la Audiencia Provincial de Navarra 129/2021, de 15 de junio [JUR\2021\195227]. 


\subsection{Criterios criminológicos}

Al hacer referencia al sexo de los delincuentes hay que tener presente que existe una amplia mayoría de infractores que pertenecen al género masculino. Un claro ejemplo de dicha afirmación viene reflejado en los resultados aportados por las estadísticas mensuales elaboradas por Instituciones Penitenciarias, las cuales, además de establecer dicha variable, muestran diferentes temáticas que se consideran útiles para desarrollar investigaciones jurídicas y criminológicas. En este sentido, volviendo al sexo de la población reclusa estatal, las cifras muestran cómo son los hombres los que cometen un mayor número de infracciones penales, no siendo necesario hacer hincapié en la naturaleza de las mismas, presentando cerca del 93\% del total de internos en los diferentes centros penitenciarios ubicados por toda la geografía española.

\section{a) Sexo}

En atención a los datos extraídos de las diferentes sentencias analizadas, se puede apreciar cómo, al igual que ocurre con las cifras obtenidas en las estadísticas elaboradas por Instituciones Penitenciarias, los hombres se configuran como el sexo predominante en lo que se refiere a los delincuentes a los que se le ha impuesto la prisión permanente revisable, afirmación que se puede observar en el siguiente gráfico, obteniendo estos una representación del $80 \%$; mientras que las mujeres constituyen un $20 \%$ del total de personas condenadas.

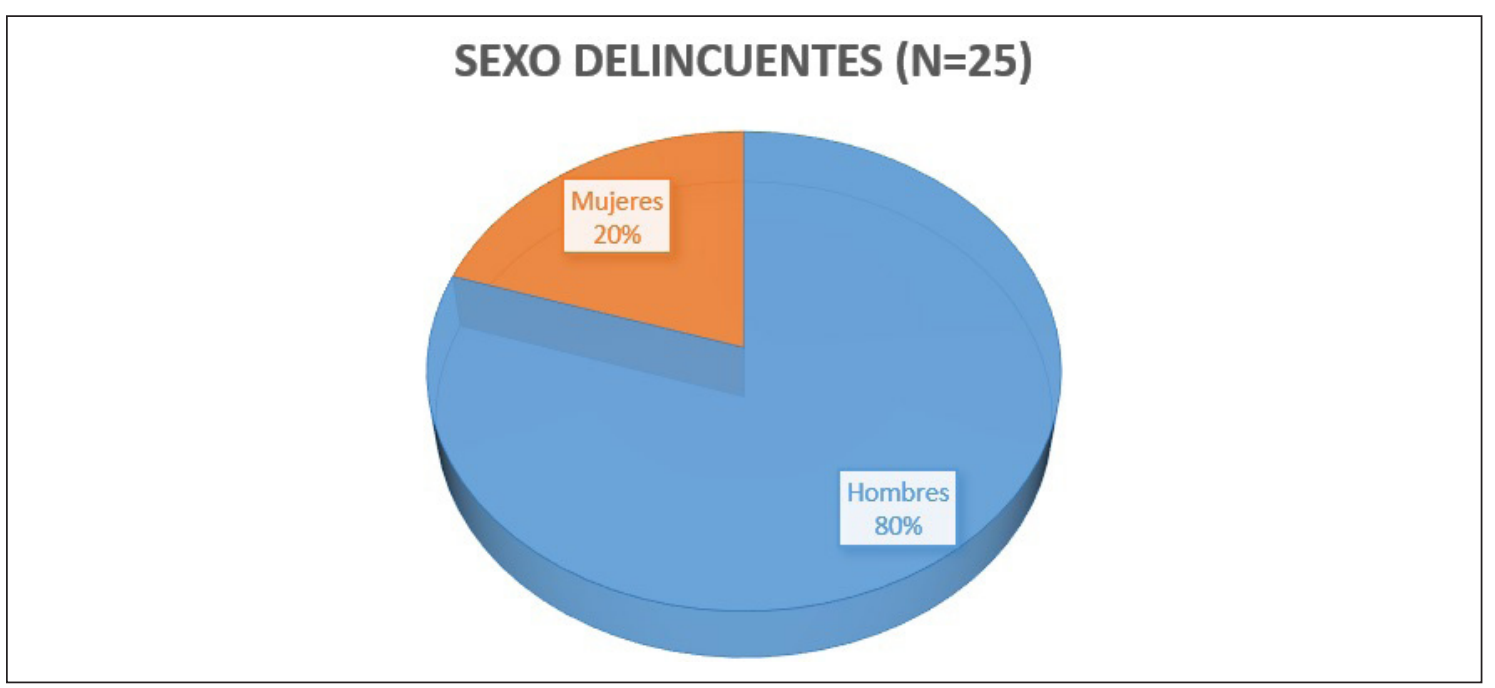

En un sentido opuesto, nos encontramos con las cifras referidas al género de las víctimas de alguna de las acciones delictivas cometidas por aquellos infractores que han sido castigados con la prisión permanente revisable. En consecuencia, los datos expuestos muestran la existencia de una mayoría de sujetos pasivos pertenecientes al sexo femenino, siendo el $53 \%$ de los casos analizados.

Teniendo en cuenta lo anteriormente mencionado, a modo de ejemplo, se exponen los datos obtenidos en la investigación elaborada por el Ministerio del Interior, presentando esta una relación directa con los delitos contra la libertad e indemnidad sexual, los 
cuales exteriorizan como las mujeres suelen ser potenciales víctimas de este tipo de infracciones penales, existiendo una amplia diferencia porcentual entre éstas, que presentan el $85 \%$ de los casos analizados, y los hombres, quienes se encuentran en el $15 \%$ restante $^{30}$.

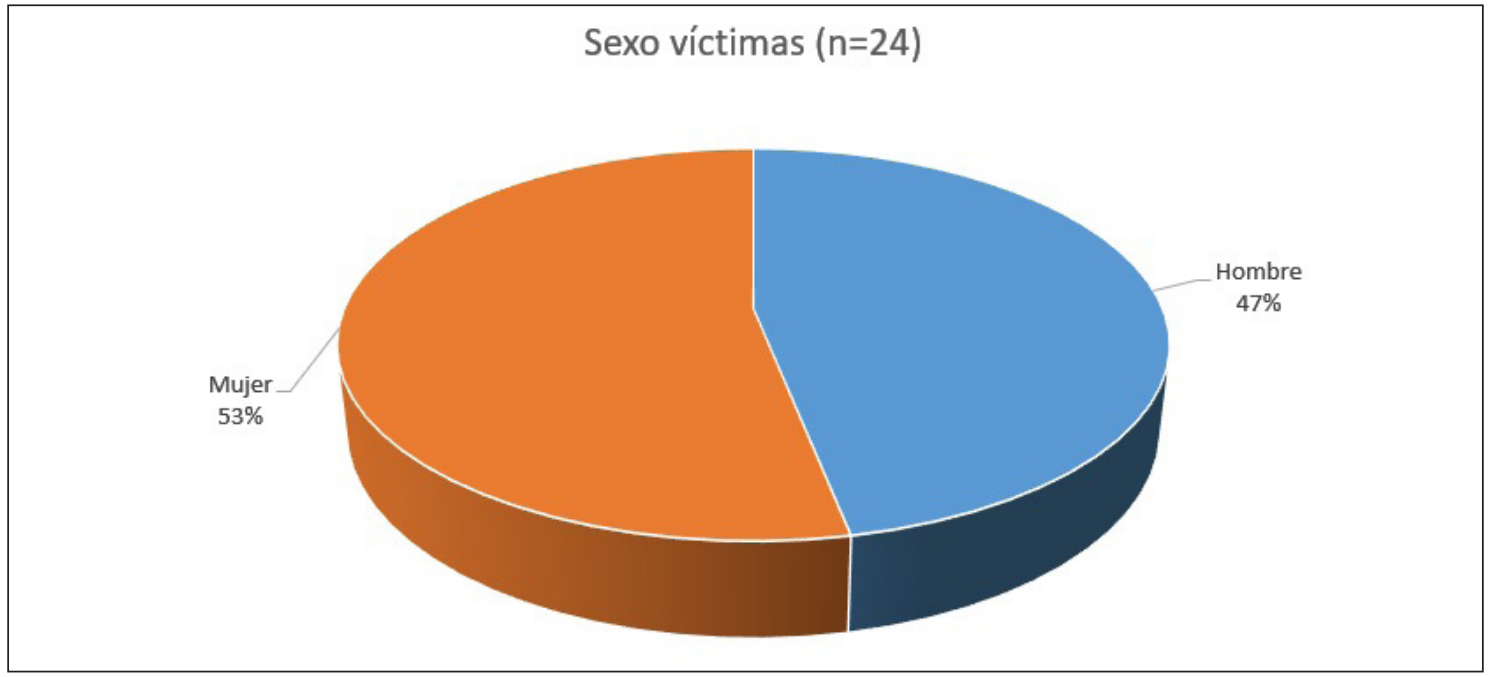

\section{b) Edad}

Por otro lado, en lo referido a la edad de aquellas personas que han sido castigadas con la prisión permanente revisable, el siguiente gráfico nos muestra como existe una cierta similitud dentro de esta variable, siendo los 37 años el único período temporal que destaca sobre el resto. En este sentido, el estudio de este precepto resulta primordial dentro de las investigaciones criminológicas, ya que, como afirma Serrano Maíllo, "la edad es uno de los dos factores más sólidamente correlacionados con la comisión de hechos delictivos" ${ }^{31}$.

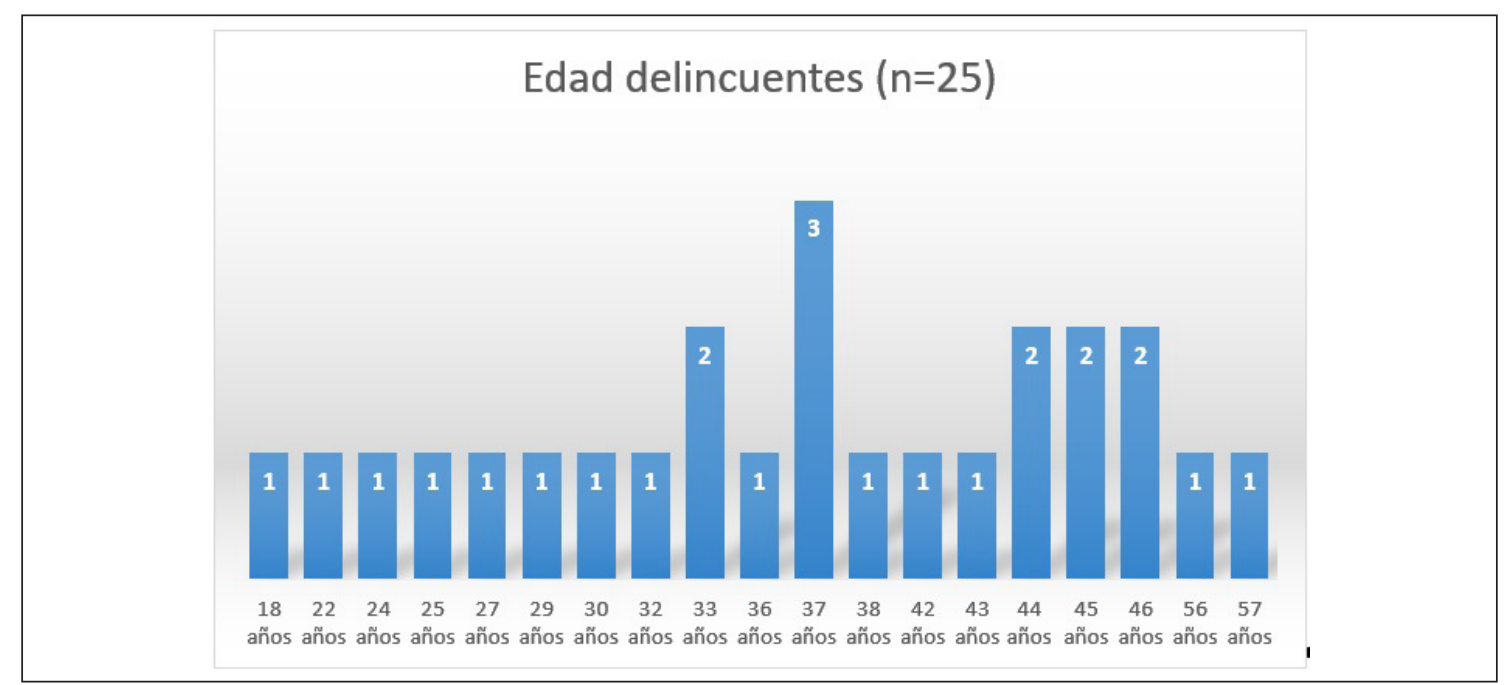

30 GOBIERNO DE ESPAÑA (Ministerio del Interior). Informe sobre delitos contra la libertad e indemnidad sexual, 2018.

31 SERRANO MAÍLlO, A., Introducción a la criminología, Madrid, 2009, pág. 569. 
A tenor de los datos extraídos, se puede apreciar como la gran mayoría de estos delincuentes se encuentran entre los 18 y los 49 años de edad, representando el $92 \%$ de los casos analizados. No obstante, como muestra el siguiente gráfico, la mayor incidencia se encuentra en aquellos individuos que presentan una edad comprendida entre los 30 y los 49 años.

En relación con lo ya descrito, la Secretaría General de Instituciones Penitenciarias ha publicado, con fecha de abril de 2020, determinados datos estadísticos, algunos de ellos referidos a la población reclusa por grupos de edad, siendo el más relevante para realizar tal comparativa el referido a las personas que se encuentran penadas por una sentencia firme ${ }^{32}$. En este sentido, los resultados presentan cierta similitud con los expuestos en el siguiente gráfico, ya que se observa cómo el 32\% de los sujetos internos en un centro penitenciario español se corresponde con aquellos que presentan edades comprendidas entre los 31 y los 40 años, cifras que se asemejan a las logradas en el supuesto que nos ocupa, el cual vendría representado por la horquilla situada entre los 30 y los 39 años, mostrándose en el $36 \%$ de los hechos examinados.

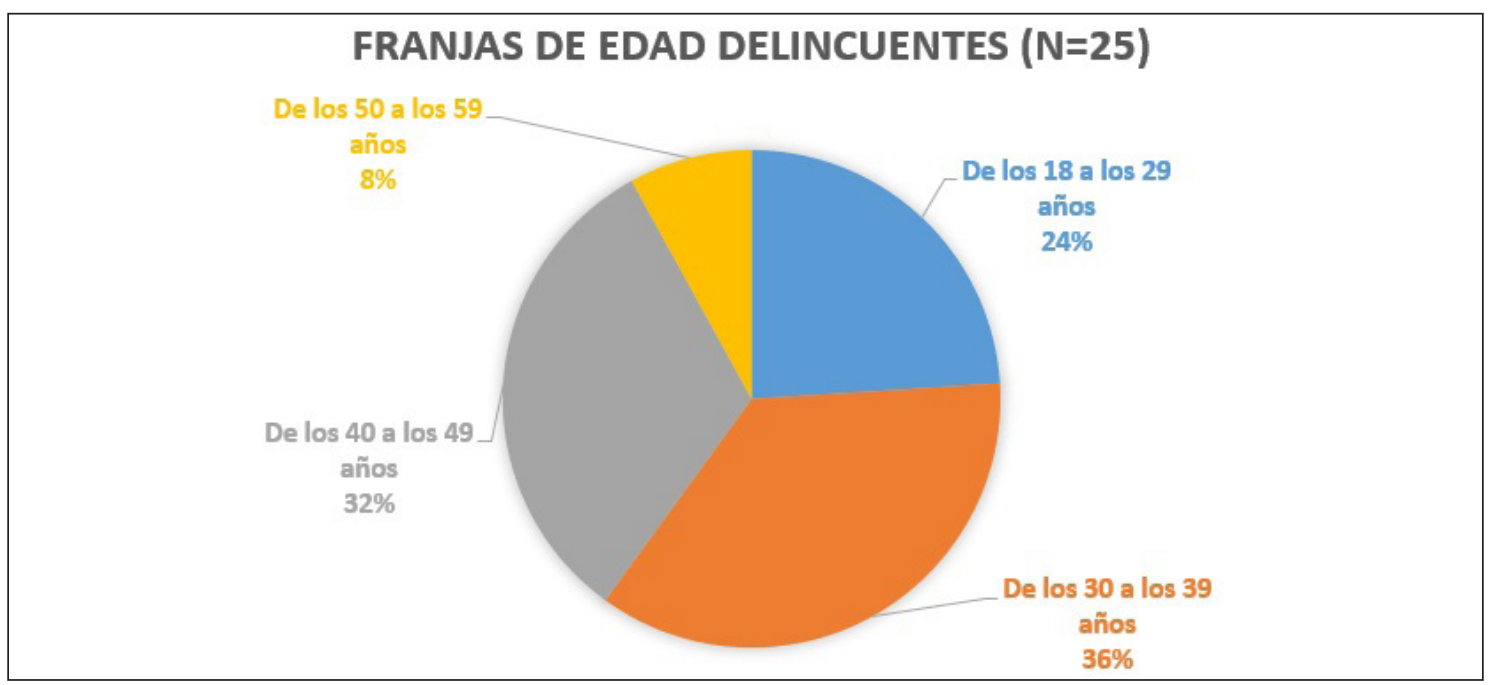

Por otro parte, en referencia a las edades de las víctimas, el análisis realizado sobre las sentencias condenatorias arroja la existencia de una relativa mayoría de menores de edad que se encuentran comprendidos dentro de esta variable. En este sentido, la vulnerabilidad de las mismas, así como la posible actuación sobre estas para llevar a cabo una conducta vengativa sobre terceras personas podrían ser los principales acontecimientos llevados a cabo por los delincuentes a la hora de acometer sus acciones contra los mencionados sujetos pasivos.

En este sentido, el estudio de la variable relacionada con la edad, ya sea en relación con el delincuente o con la víctima, reviste una gran importancia dentro de la criminología, siendo un elemento fundamental a la hora de establecer los posibles perfiles criminales. En este sentido, Serrano Maíllo dispone que "después del sexo, la edad es el correlato

32 Información obtenida de la página web: http://www.institucionpenitenciaria.es. 
más sólido del delito" ${ }^{33}$, poniendo de manifiesto con ello la gran relevancia de la misma dentro de las investigaciones realizadas por la doctrina criminológica.

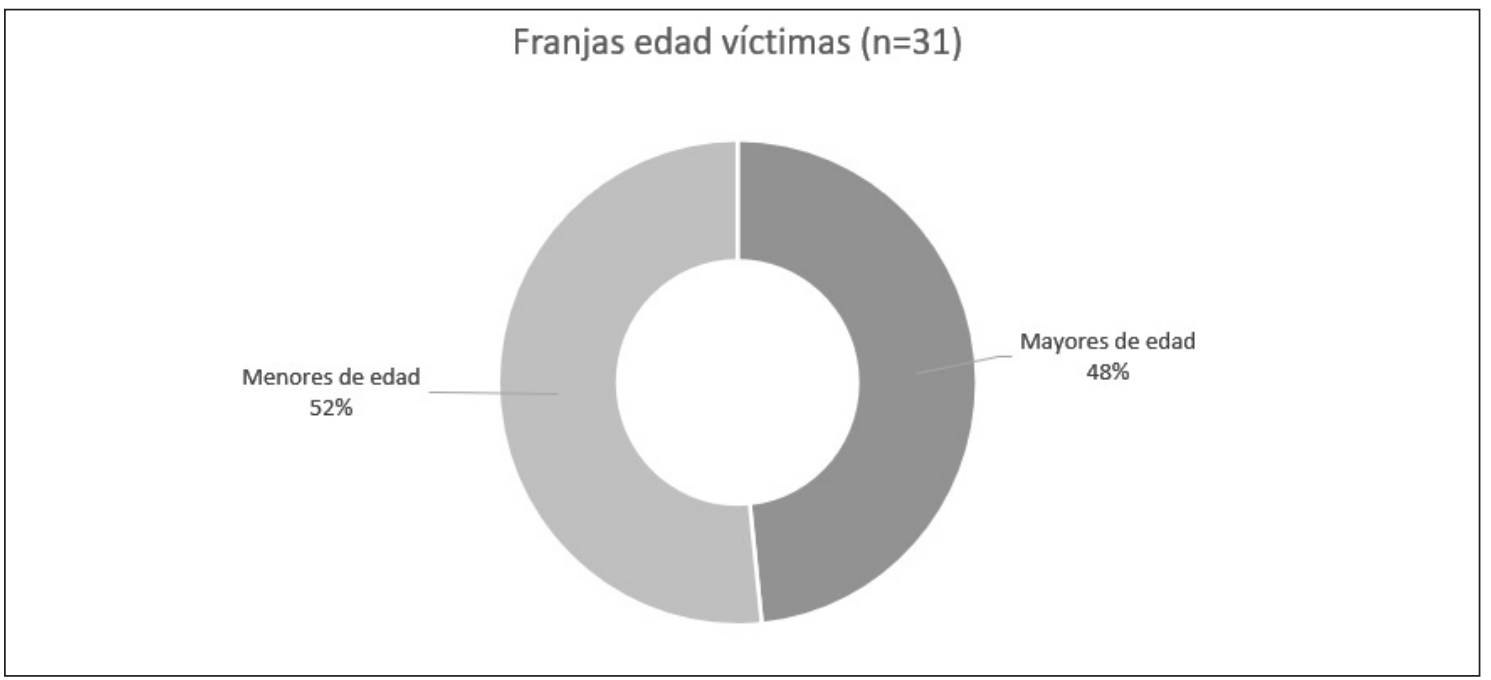

Posteriormente, tras desglosar los porcentajes descritos en el gráfico anterior, se aprecia como la distribución por edades nos revela unas cifras muy similares, no existiendo una etapa temporal concreta que se pueda llegar a considerar propicia para enmarcarse dentro de las tipologías victimales de este tipo de criminales.

Así, en atención a los datos expuestos en el siguiente gráfico, y en referencia a las afirmaciones realizadas, se puede apreciar la existencia de una especial vulnerabilidad en un conjunto determinado de víctimas, dato que quedaría reflejado en el elevado número de sujetos pasivos menores de 18 años, haciendo especial hincapié en aquellos que no llegan a los 10 años, representando estos el 35,48\% de los casos analizados.

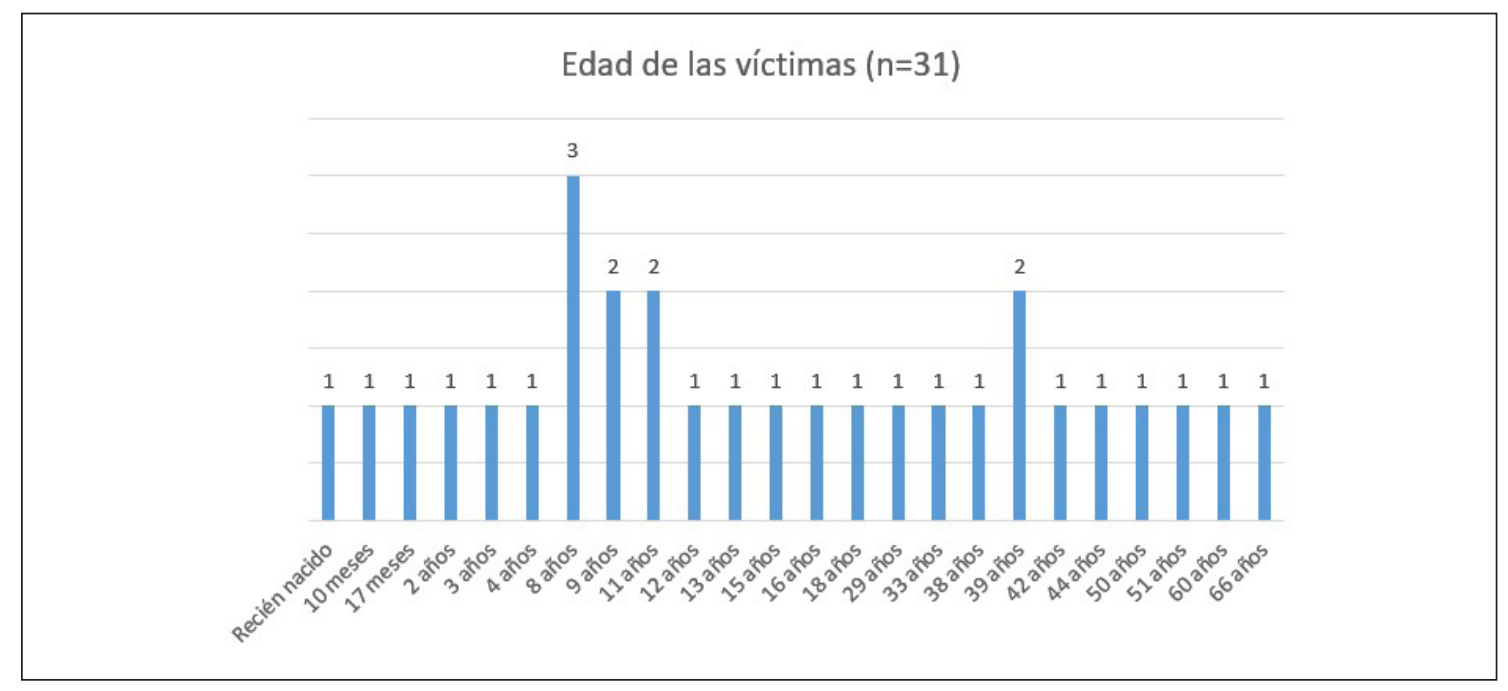

33 SERRANO MAÍLLO, A., "Actos de fuerza o engaño y autocontrol. Un test de una teoría general del delito con una muestra pequeña de delincuentes juveniles”, en Revista Electrónica de Ciencia Penal y Criminología, 13, 2009, págs. 1-38. 


\section{c) Relación entre víctima y victimario}

El estudio del vínculo previo existente entre el sujeto activo y el pasivo resulta fundamental, ya que de ese análisis se podrán extraer determinados datos que permitirán llevar a cabo un estudio pormenorizado de las circunstancias que acompañaron a la acción delictiva. En este sentido, resulta de gran importancia intentar recabar toda aquella información que pueda ayudar a intentar comprender el motivo por el cual una determinada persona ha decidido actuar de forma violenta sobre otra.

En consecuencia, en el siguiente gráfico se puede observar como existe una amplia mayoría de casos en los que el delincuente decide actuar contra su propio/a hijo/a, hecho de extrema gravedad que persigue, entre otras acciones, dañar psicológicamente a terceras personas, las cuales se pueden llegar a sentir responsables de los acontecimientos ocurridos.

En atención a los datos obtenidos tras el análisis de las sentencias condenatorias, se extraen varios eventos de especial consideración: i) de las 31 acciones estudiadas, sólo en 5 de ellas se aprecia cómo no existe una relación previa entre el delincuente y la víctima; ii) en referencia a las relaciones sentimentales previas, las cifras expuestas muestran como el 12,90\% hace mención a este tipo de acontecimiento criminal; iii) en la gran mayoría de casos analizados, las acciones delictivas se producen dentro de un contexto familiar, con independencia del rol que ejerza cada uno de los sujetos participantes dentro del hecho delictivo.

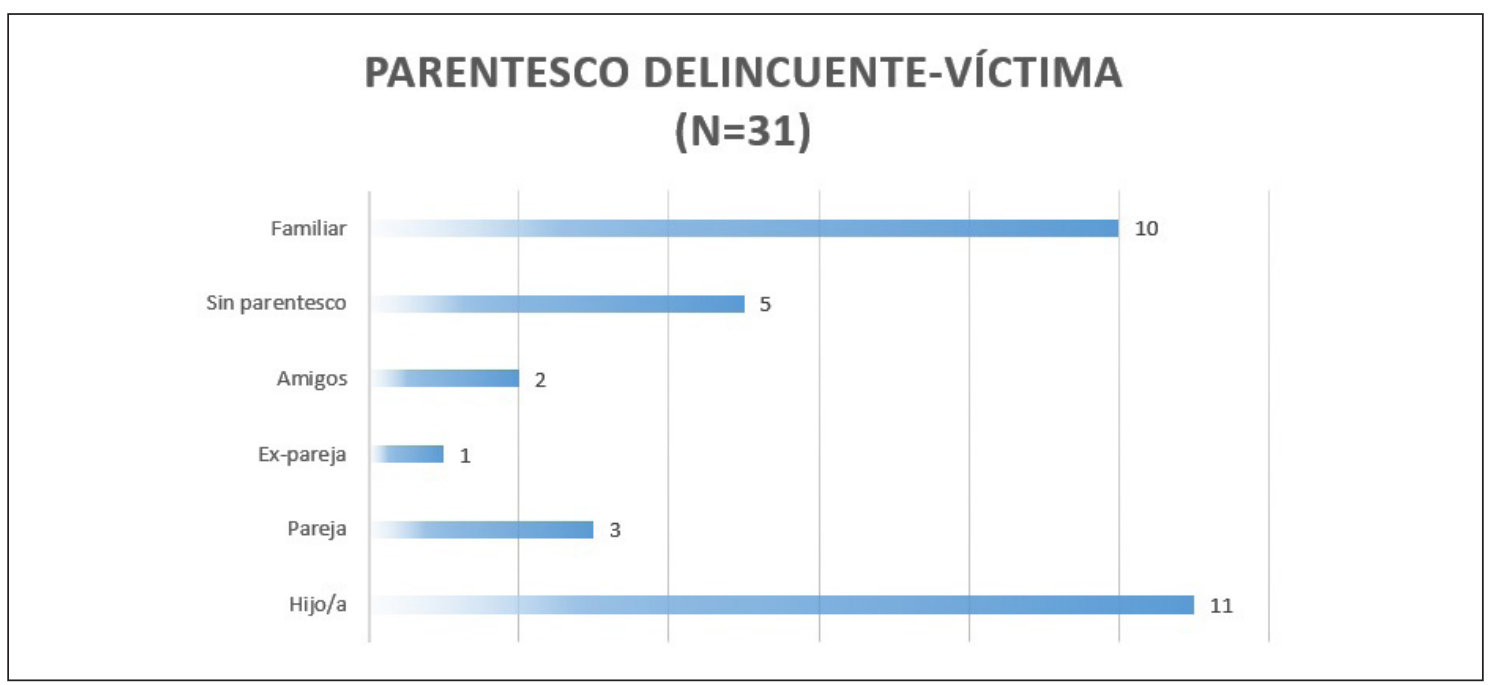

\section{d) Comunidad Autónoma donde ocurre el acto delictivo}

En referencia a la localización territorial donde se han desarrollado las acciones delictivas que han propiciado la imposición de la prisión permanente revisable, el estudio de las sentencias condenatorias nos muestra cómo serán Andalucía, Comunidad Valenciana y Galicia donde tiene una mayor incidencia este tipo de condena. En consecuencia, resulta complejo establecer los motivos por los cuales en dichos emplazamientos geográficos se llevan a cabo una reiteración de conductas gravosas, las cuales llevan aparejada la imposición de este tipo de pena. 


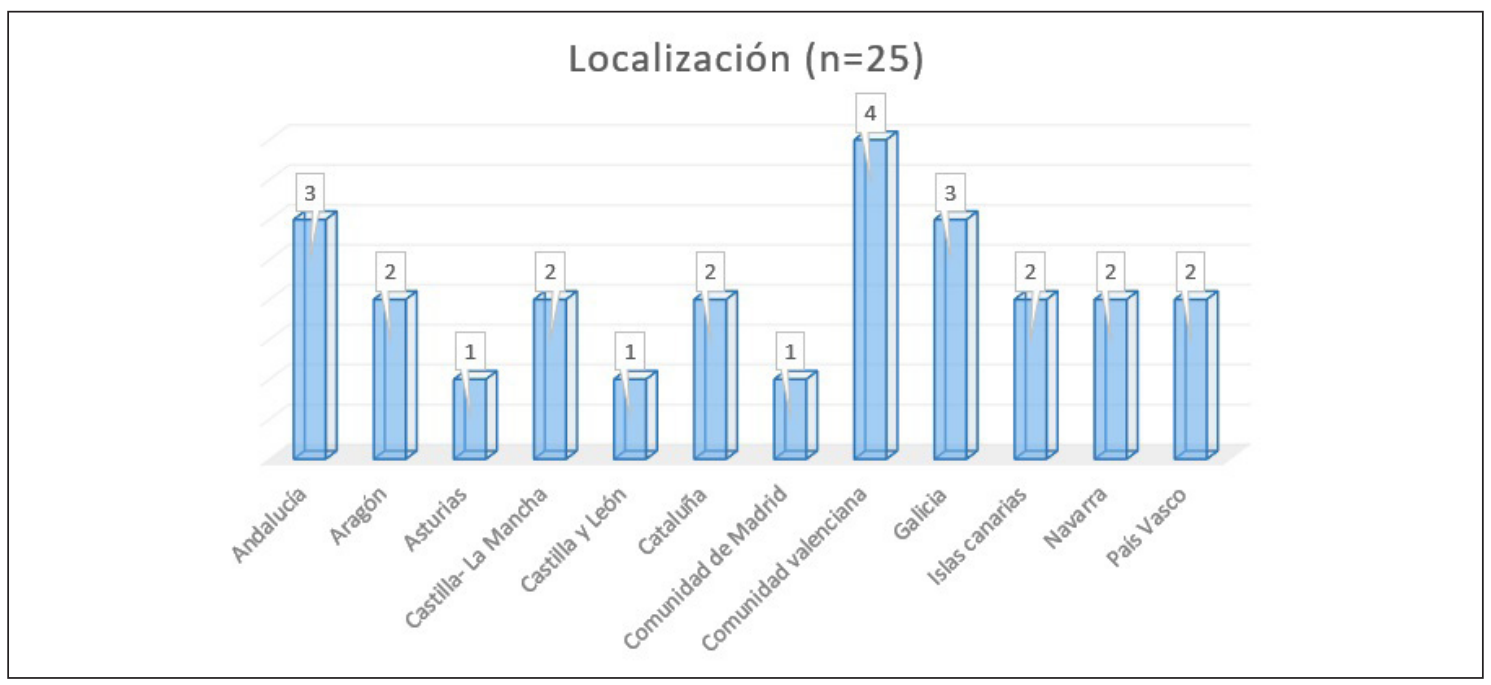

No obstante, para calcular el verdadero efecto de la misma, resulta recomendable realizar las respectivas tasas de criminalidad, hecho que ayudará a determinar en qué comunidad autónoma tiene una mayor repercusión este tipo de condena. En este sentido, una vez realizada tal acción con los datos poblacionales obtenidos en el Instituto Nacional de Estadística para el año 2020 34 , en el siguiente gráfico se puede comprobar cómo será Galicia la región que presenta unos porcentajes más elevados, siendo esta comunidad la primera que impuso la prisión permanente revisable en nuestro país.

\section{Tasa de criminalidad 2020}
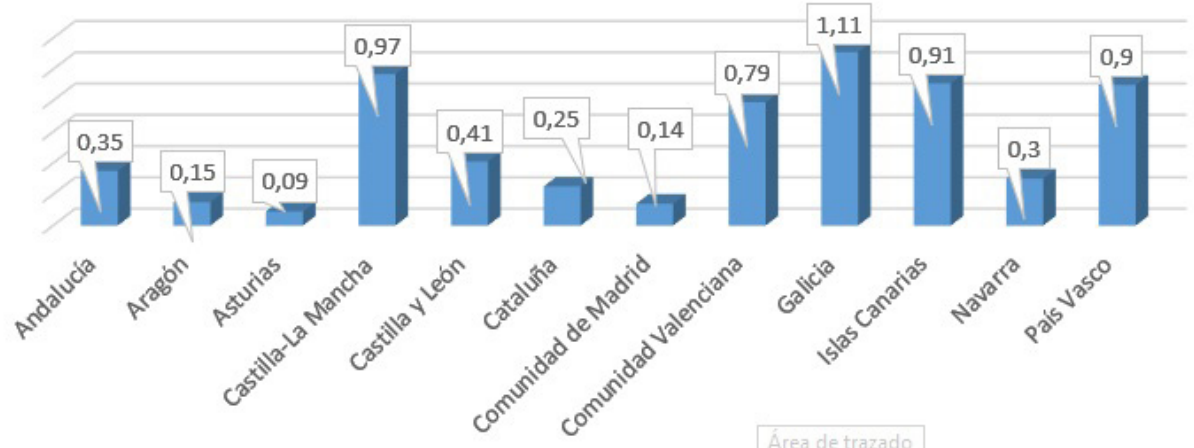

\section{CRITERIOS PENALES}

Como se ha podido señalar en apartados anteriores, se podría considerar que la prisión permanente revisable es una condena de nueva creación dentro de la normativa penal española, ya que no fue hasta la reforma de 2015 cuando se comenzó a regular en la

34 Recurso electrónico disponible en: https://www.ine.es 
misma. En este sentido, teniendo en cuenta esta consideración, resulta comprensible determinar que dicho castigo no ha podido ser impuesto con anterioridad a la mencionada modificación.

En referencia a lo indicado, en el siguiente gráfico se puede apreciar como la gran mayoría de sentencias en las que se impone dicha condena tuvieron lugar durante el año 2019, existiendo un incremento paulatino a lo largo de los años completos desde su implantación, salvo durante el año 2020, donde se produjo un ligero descenso, apenas significativo, en la imposición de dicha condena. No obstante, cabe matizar que, durante la realización de este trabajo, el año 2021 no había concluido, por lo que podría darse la circunstancia que el número de sentencias siguiera aumentando.

\section{AÑO IMPOSICIÓN CONDENA ( $\mathrm{N}=25)$}

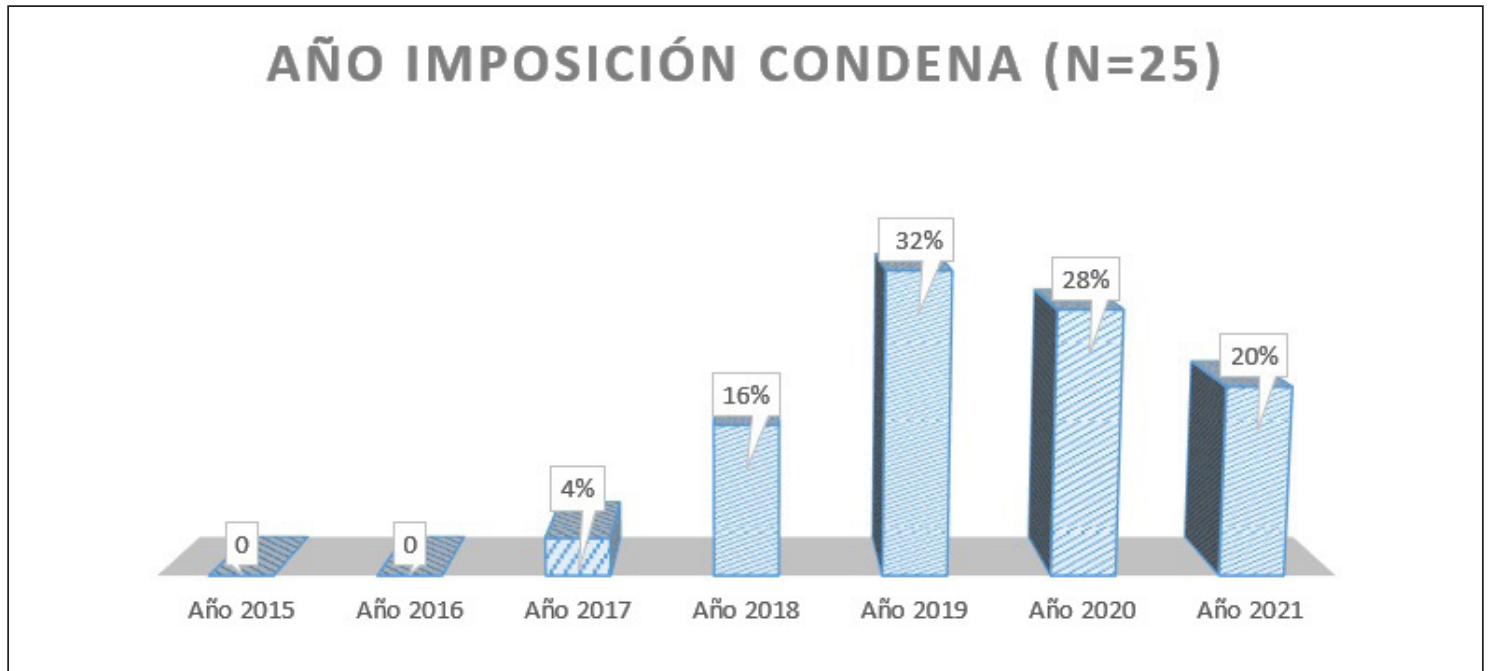

Las personas que han sido castigadas con la imposición de este tipo de condena suelen acompañar estos actos con la comisión de otro tipo de acción delictiva, siendo esta generalmente de otra naturaleza. En este sentido, en atención al estudio realizado sobre las diversas sentencias impuestas, las lesiones suelen ser las infracciones penales que tienen una mayor representación dentro del conglomerado de trasgresiones cometidas, las cuales representan un $32,35 \%$ del total de hechos realizados. Por otro lado, con una representatividad media se encontrarían los delitos contra la libertad e indemnidad sexual y los correspondientes al homicidio y sus formas con un 20,58\%. Finalmente, existe una caterva de acontecimientos delincuenciales que presentan unas cifras que escaso rigor simbólico; contra el patrimonio y el orden socioeconómico $(8,82 \%)$; de las torturas y otros delitos contra la integridad moral y contra el orden público $(5,88 \%)$ y, finalmente, aquellos que son cometidos contra la libertad y contra la Constitución (2,94\%, cada uno de ellos).

En lo relativo a los delitos identificados dentro de la sección destinada al homicidio y sus formas, cabe mencionar que los mismos hacen referencia a otras acciones delictivas diferentes a la principal, es decir, nos podemos encontrar ante una situación en la que una persona castigada con la prisión permanente revisable haya cometido otros delitos, los cuales se engloban dentro de la mencionada tipificación penal, pero que, por no cumplir los requisitos exigidos para la imposición de la prisión permanente revisable, el correspondiente tribunal haya decidido castigarla con una condena diferente. 


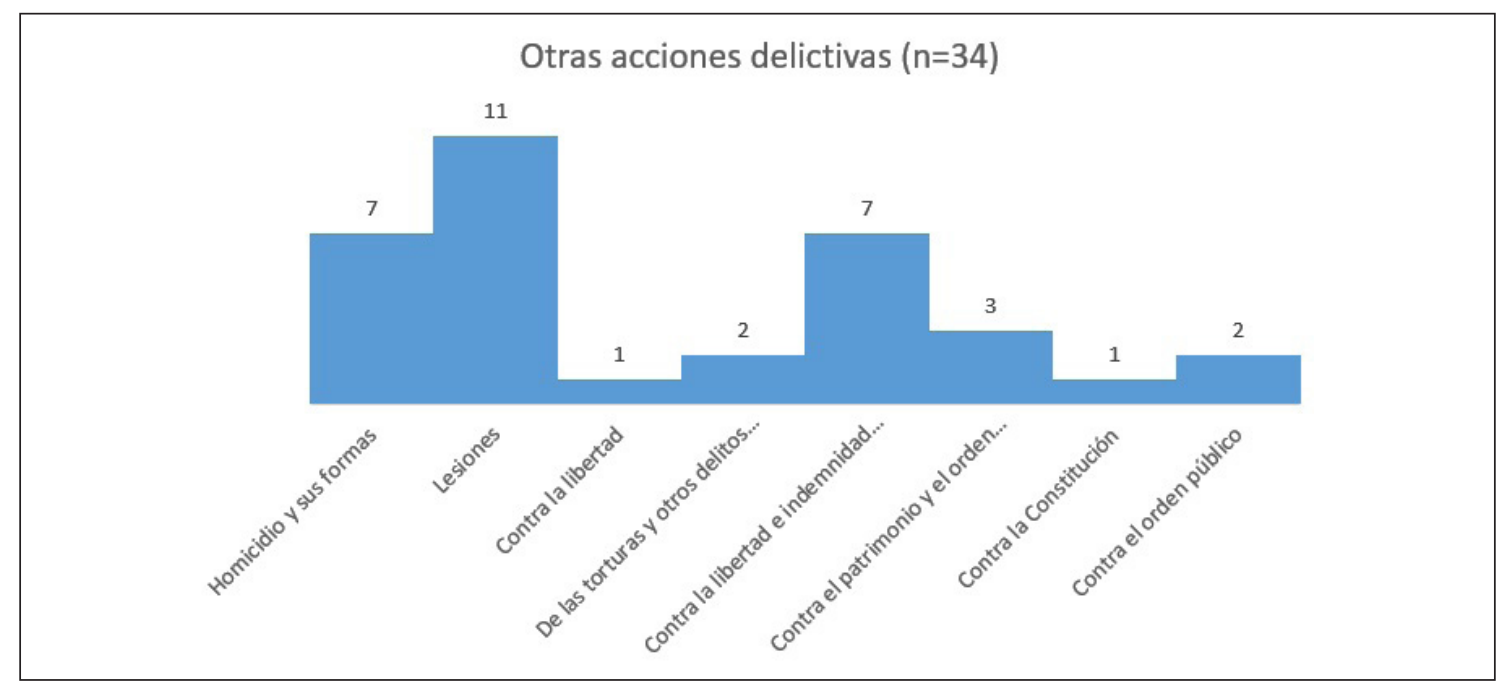

Posteriormente, en referencia a los posibles antecedentes penales que presentan estos delincuentes, y en atención a lo detallado en el siguiente gráfico, cabe destacar que existe una amplia mayoría de los sujetos analizados que no han cometido acciones delictivas con anterioridad al hecho criminal por el que fueron condenados. En este sentido, resulta conveniente señalar la importancia que conlleva proceder al estudio de la mencionada variable, ya que, el hecho de dar publicidad a los mismos puede generar una señal identificativa en el delincuente a la hora de intentar luchar por integrarse en la sociedad. Así, Larrauri Pijoan dispone que "para una persona el estigma perpetuo de "delincuente" y tolerar la publicidad de su condena, como una marca, disminuyen considerablemente sus posibilidades de reintegrarse en la sociedad"35.

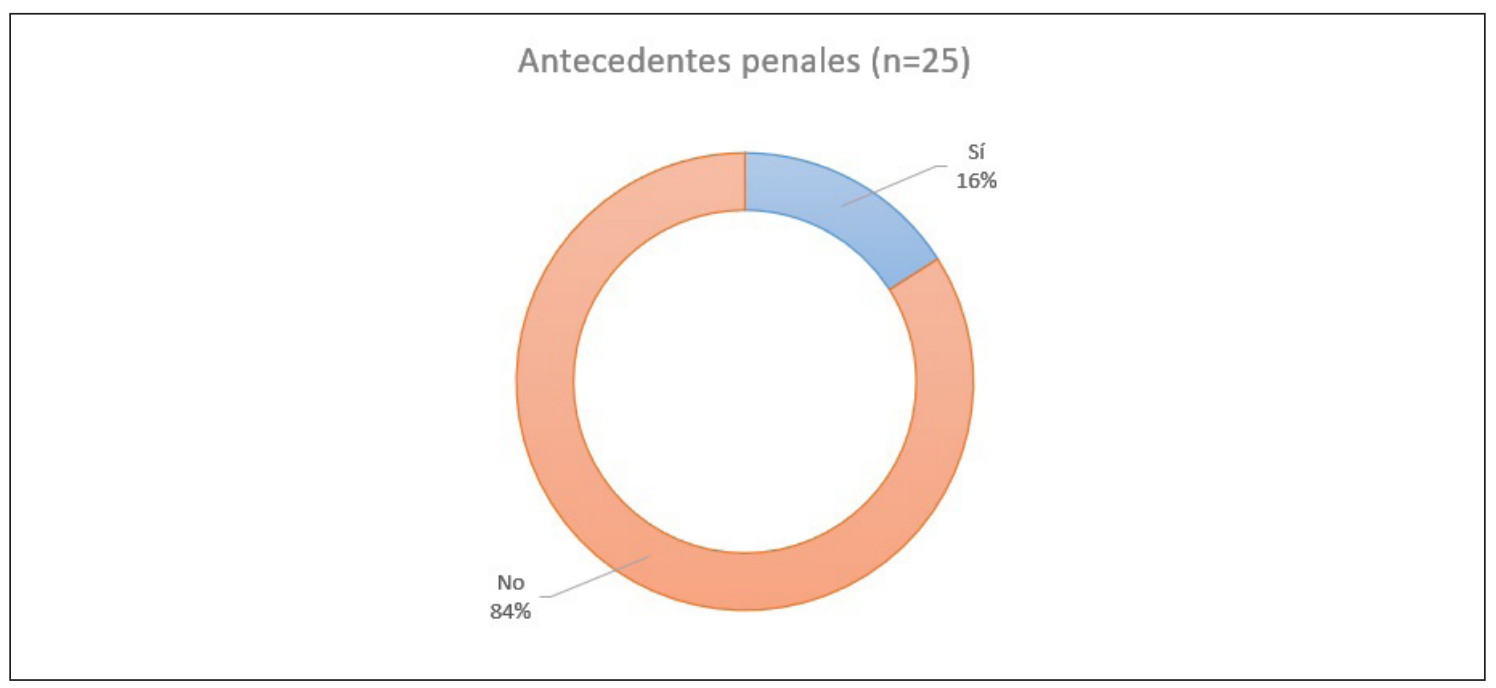

No obstante, en referencia a las variables expuestas anteriormente, cabe destacar que hay en determinados casos en los que la sentencia ha sido revocada en su totalidad o

35 LARRAURI PIJOAN, E., “Antecedentes penales”, en Eunomía. Revista en Cultura de la Legalidad, vol. 8, 2015, págs. 153-159. 
parcialmente. A modo de ejemplo, conviene señalar lo ocurrido en las sanciones impuestas a Patrick Nogueira, quien, en un principio, fue condenado a cuatro penas de prisión permanente revisable, pero que, tras una revisión de la sentencia impuesta por la correspondiente Audiencia Provincial, el Tribunal Superior de Justicia de Castilla-La Mancha decidió sustituir tres de las mismas por penas de veinticinco años de prisión, quedando condenado dicho autor a una sola pena de prisión permanente revisable ${ }^{36}$.

\section{CONCLUSIONES}

Una vez realizada la exposición de la investigación desarrollada, la cual tiene su punto de partida en el análisis de los diferentes dictámenes expuestos por la doctrina jurídica y por la criminológica, y concluyendo con el estudio de las sentencias en las que se condenó a la prisión permanente revisable a los culpables de diversas acciones criminales, considero preciso especificar cuáles son las principales hipótesis que he extraído tras la realización del mencionado estudio.

1. La constante evolución de la sociedad hace que surjan nuevas formas delictivas, lo que provoca una incesante modificación del Código Penal, pudiendo llegar a ser considerada dicha norma como una ley mediática, consecuencia directa de la presión que ejerce la colectividad. En este sentido, en base al conocimiento que los políticos suelen tener de estas demandas sociales, estos suelen utilizar en sus programas electorales ciertas novedades penales para intentar obtener unas mayores ganancias electorales. En consecuencia, la prisión permanente revisable es fruto de lo que podríamos definir como populismo punitivo.

2. A pesar del gran espacio temporal existente entre una y otra, la prisión permanente revisable se puede considerar como una pena que presenta una cierta continuidad a la antigua cadena perpetua. No obstante, existen ciertos matices que distinguen a estos dos correctivos. En este sentido, considero que en el propio término utilizado para nombrar al castigo introducido a partir de la Ley Orgánica 1/2015, de 30 de marzo, por la que se modifica la Ley Orgánica 10/1995, de 23 de noviembre, del Código Penal, se muestra un cierto distanciamiento con el castigo a perpetuidad, ya que el hecho de ser "revisable" hace que el sujeto condenado pueda albergar algún tipo de esperanza de poder disfrutar en un futuro de la vida en libertad.

3. Sin necesidad de llegar a hacer referencia al derecho comparado, conviene señalar que la mencionada condena existe en otros países europeos, las cuales presentan ciertas similitudes a la descrita en esta investigación. No obstante, resulta recomendado destacar que España presenta un periodo mínimo de cumplimiento superior al existente en la media europea.

4. La incorporación de dicha condena dentro del articulado de nuestro Código Penal ha llevado aparejado desde sus inicios cierta polémica, ya que existe una mayoría de miembros de la doctrina jurídica que se muestran contrarios a la

36 Sentencia del Tribunal Superior de Justicia de Castilla-La Mancha 16/2019, de 13 de junio [JUR\2019\222250]. 
misma. A pesar de ello, conviene destacar que también hay voces que orientan sus argumentos a favor de la prisión permanente revisable, lo que genera un continuo debate sobre la idoneidad o no de la mencionada pena.

5. La incidencia de la prisión permanente revisable dentro de la legislación penitenciaria es muy severa, ya que, en atención a las características expuestas en la configuración de dicha condena, se aprecia cómo se pueden ver afectados los fines primordiales perseguidos por los estatutos que rigen dentro de prisión, siendo estos los referidos a la reeducación y a la reinserción social.

6. Como ya se ha mencionado a lo largo de la investigación, los datos obtenidos a partir de las diferentes sentencias condenatorias analizadas no contemplan la totalidad de los hechos ocurridos en el año 2021, acontecimiento que podría generar una modificación en alguno de los gráficos recogidos en este estudio. No obstante, cabe destacar que, desde su incorporación en el Código Penal, se ha apreciado un aumento en la imposición de la prisión permanente revisable, hecho que generará unas cifras durante los próximos años muy llamativas, ya que, por diferentes motivos, se seguirán cometiendo delitos de especial gravedad en España.

7. En referencia a las particularidades personales, penales y criminológicas de las personas a las que se les impone este tipo de condena, cabe mencionar que, en atención a los datos obtenidos del análisis de las diferentes sentencias condenatorias, suelen ser hombres; con edades comprendidas entre los treinta y los cuarenta y nueve años; ostentan cierto parentesco con sus víctimas, las cuales suelen ser hijos/as del agresor o familiares cercanos; no presentan antecedentes penales y, además de los crímenes por los cuales han sido penados con dicha condena, suelen realizar otro tipo de acciones delictivas, siendo los delitos de lesiones los más repetidos.

8. Finalmente, en atención a los sujetos pasivos de este tipo de delitos, cabe mencionar que suelen ser mujeres, con las cuales los agresores guardan algún tipo de relación familiar, siendo en su mayoría personas menores de edad, hecho que podría tener una relación directa con la mayor vulnerabilidad de las mismas.

\section{BIBLIOGRAFÍA}

Acale SÁnchez, M. La prisión permanente revisable: ¿pena o cadalso?, Madrid, 2016.

ANDRÉs LASO, A. "Legislación penal, procesal penal y penitenciaria tras la guerra civil española", en Revista Jurídica de Castilla y León, 2015.

Beccaria, C. Tratado de los delitos y de las penas, Madrid, 2015.

CÁmara Arroyo, S. y Fernández Bermejo, D. La prisión permanente revisable: el ocaso del humanitarismo penal y penitenciario, 2016.

CASAls Fernández, A. "La ejecución penitenciaria de la pena de prisión permanente revisable", en Anuario de derecho penal y ciencias penales, vol. LXXII, 2019.

CASAls Fernández, A. La prisión permanente revisable, Madrid, 2019.

Cervelló Donderis, V. Prisión perpetua y de larga duración. Régimen jurídico de la prisión permanente revisable, Valencia, 2016. 
Cuello Contreras, J. y Mapelli Caffarena, B. Curso de Derecho Penal. Parte General, Madrid, 2015.

Cuerda Riezu, A. Cadena perpetua y las penas muy largas de prisión: Por qué son inconstitucionales en España, Barcelona, 2011.

De Vicente Martínez, R. “La Ley Orgánica General Penitenciaria 40 años después”, en Anuario de derecho penal y ciencias penales, vol. LXXII, 2019.

FERnÁNDez Bermejo, D. "Del sistema progresivo a la individualización científica. La elaboración de la Ley General Penitenciaria y la relevancia del bienio 1978-1979 en el derecho penitenciario", en Anuario de derecho penal y ciencias penales, vol. LXXII, 2019.

GÁLVEZ JimÉnEZ, A. "La aplicación de la prisión permanente revisable ex LO 1/2015, de 1 de julio”, en Revista Internacional de Doctrina y Jurisprudencia, vol. 18, 2018.

García-Pablos De Molina, A. "La aportación de la criminología”, en Eguzkilore, vol. 3, 1989.

Gimbernat Ordeig, E. “Contra la prisión permanente revisable”, en Anuario de derecho penal y ciencias penales, vol. 71, 2018.

GonzÁlez Collantes, T. “Las penas de encierro perpetuo desde una perspectiva histórica”, en Foro, Nueva época, vol. 18, 2015.

JaÉn VAllejo, M. y Perrino Pérez, A.L. La reforma penal de 2015. (Análisis de las principales reformas introducidas en el Código Penal por las Leyes Orgánicas 1 y 2/2015, de 30 de marzo), Madrid, 2015.

Juanatey Dorado, C. Manual de derecho penitenciario, Madrid, 2016.

Larrauri Pijoan, E. “Antecedentes penales”, en Eunomía. Revista en Cultura de la Legalidad, vol. 8, 2015.

López Peregrín, C. "Más motivos para derogar la prisión permanente revisable", en Revista Electrónica de Ciencia Penal y Criminología, 2018.

Manzanares Samaniego, J.L. "Las penas en la Ley Orgánica 1/2015, de 30 de marzo”, en La Ley Penal, $2782 / 2015$.

Mapelli CafFarena, B. Las consecuencias jurídicas del delito. Navarra, 2005.

Morillas Cueva, L. "Reflexiones sobre el derecho penal del futuro", en Revista Electrónica de Ciencia Penal y Criminología, vol. 04-06, 2002.

Pascual Matellán, L. "La prisión permanente revisable. Un acercamiento a un derecho penal deshumanizado", en Clivatge. Estudis i testimonis sobre el conflicte $i$ el canvi socials, 2015.

Ríos Martín, J.C. "La pena de prisión permanente revisable. La suspensión y sustitución de las penas", en Cuadernos penales. José María Lidón, vol. 10, 2014.

Roig Torres, M. La cadena perpetua en el derecho alemán y británico. La prisión permanente revisable, Madrid, 2016.

SAnz Delgado, E. "El trabajo penitenciario y el principio de flexibilidad”, en García Valdés, C., Valle Mariscal de Gante, M., Cuerda Riezu, A.R., Martínez Escamilla, M., y Alcácer Guirao, R., (Coords.), Estudios penales en homenaje a Enrique Gimbernat, vol. 2., Madrid, 2008.

Serrano Gómez, A. y Serrano Má́llo, I. Constitucionalidad de la prisión permanente revisable y razones para su derogación, Madrid, 2016.

Serrano Maíllo, A. “Actos de fuerza o engaño y autocontrol. Un test de una teoría general del delito con una muestra pequeña de delincuentes juveniles", en Revista Electrónica de Ciencia Penal y Criminología, 13, 2009.

SERrano Maíllo, A. Introducción a la criminología, Madrid, 2009. 